\title{
Mental health concerns during the COVID-19 pandemic as revealed by helpline calls
}

https://doi.org/10.1038/s41586-021-04099-6

Received: 19 May 2021

Accepted: 6 October 2021

Published online: 17 November 2021

Check for updates

\author{
Marius Brülhart ${ }^{1,2 \bowtie}$, Valentin Klotzbücher ${ }^{3}$, Rafael Lalive ${ }^{1,2}$ \& Stephanie K. Reich ${ }^{3}$
}

Mental health is an important component of public health, especially in times of crisis. However, monitoring public mental health is difficult because data are often patchy and low-frequency ${ }^{1-3}$. Here we complement established approaches by using data from helplines, which offer a real-time measure of 'revealed' distress and mental health concerns across a range of topics ${ }^{4-9}$. We collected data on 8 million calls from 19 countries, focusing on the COVID-19 crisis. Call volumes peaked six weeks after the initial outbreak, at $35 \%$ above pre-pandemic levels. The increase was driven mainly by fear (including fear of infection), loneliness and, later in the pandemic, concerns about physical health. Relationship issues, economic problems, violence and suicidal ideation, however, were less prevalent than before the pandemic. This pattern was apparent both during the first wave and during subsequent COVID-19 waves. Issues linked directly to the pandemic therefore seem to have replaced rather than exacerbated underlying anxieties. Conditional on infection rates, suicide-related calls increased when containment policies became more stringent and decreased when income support was extended. This implies that financial relief can allay the distress triggered by lockdown measures and illustrates the insights that can be gleaned from the statistical analysis of helpline data.
The state of population mental health is difficult to measure. This could lead policymakers to neglect mental health issues relative to aspects that can be measured more easily-especially during fast-moving crisis situations ${ }^{1-3}$. We propose using helpline data as a source of real-time information on the state of public mental health. Helpline data have two main advantages. First, helpline calls can be considered as a manifestation of revealed distress and mental health concerns. Callers incur the mental and time cost of reaching out without having been prompted to do so. Therefore, helpline calls resemble clinical data by offering a measure of mental health that is unaffected by researchers' study design and framing. Second, information about helpline calls is recorded digitally with daily frequency and covers a wide range of conversation topics.

Telephone helplines are well-established institutions for mental health protection and suicide prevention in many countries, and they offer support immediately, anonymously, cheaply and accessibly ${ }^{10-12}$ .Some helplines specialize in particular issues such as suicide, children or violence against women. Suicide helplines, for example, have been shown to reduce suicide rates ${ }^{13}$, and call volumes of suicide prevention helplines have been shown to relate to the incidence of actual suicides $^{14}$.

Using this approach in relation to the COVID-19 crisis, we documented the growth and composition of helpline calls as well as their pandemic-related determinants. Helplines take on particular relevance in a pandemic, when face-to-face contacts carry infection risks and may even be impossible owing to stay-at-home orders ${ }^{4-9}$. We collected data from 23 helplines in 14 European countries, the USA, China, Hong Kong, Israel and Lebanon. The total dataset covers 8 million individual calls made between 2019 and early 2021 (Extended Data Table 1). The panel structure of the data enables us to exploit differences in the timing of local infection waves and policy measures to isolate their separate effects on helpline calls. This is a first-order issue for policymakers, as interventions designed to contain infections might also affect mental health by exacerbating unemployment, financial stress, loneliness, relationship problems and pre-existing mental vulnerabilities. These are, in turn, well-recognized risk factors for suicide ${ }^{15-22}$.

We consider the analysis of helpline calls as a complement, and not a substitute, for established approaches. Mental health surveys ${ }^{23-26}$ and suicide statistics ${ }^{27-29}$ are highly informative, but they tend to be low frequency and available with a lag. Higher-frequency monitoring has been performed in the context of the COVID-19 pandemic on the basis of online searches as recorded by Google Trends ${ }^{30-33}$, by tracking visits to emergency departments ${ }^{34,35}$, and by monitoring calls to the police for help with domestic disputes ${ }^{36-38}$. Helpline data contribute a measurement tool that is both broadly available and well targeted on the mental health concerns of a particularly vulnerable segment of the population.

\section{Results}

Increased call volumes across helplines

When we pool and size-weight the data for the 21 helplines for which we have daily data (Extended Data Table 1a, b), we observe a peak call volume, reached six weeks after the outbreak of the pandemic, that exceeds the pre-pandemic level by $35 \%$ ( $95 \%$ confidence interval (CI): 22.6, 48.3; $P<0.001$ ) (Fig. 1a). With the country-specific outbreak 

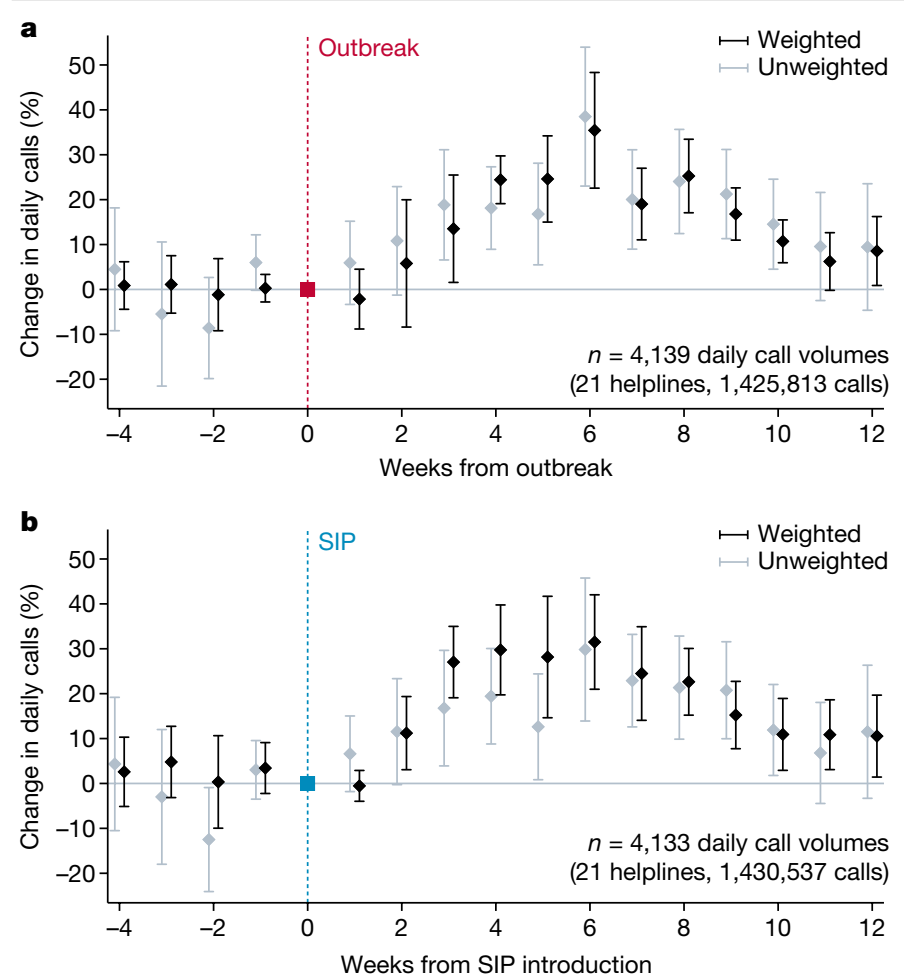

Fig. 1 | Evolution of total helpline call numbers during the first wave. a,b, Estimated coefficients for week indicators with $95 \%$ confidence intervals. The dependent variable is $\ln$ (Calls). The sample includes daily data for 21 helplines during the period from 4 weeks before to 12 weeks after the event date in early 2020, and for 17 of the 21 helplines, the corresponding days in 2019. Average percentage change in call volumes relative to reference week 0 .a, Week 0 is when the cumulative number of SARS-CoV-2 infections exceeded 1 per 100,000 population $^{39} . \mathbf{b}$, Week 0 is when SIP orders were introduced ${ }^{40}$. Results show data weighted by total number of calls recorded for each helpline during the sample period (black) and unweighted models (grey) (Methods, equation (1)).

defined as the date when more than 1SARS-CoV-2 infection per 100,000 inhabitants was recorded ${ }^{39}$, we see a significant increase of $13.5 \%(95 \%$ $\mathrm{CI}: 1.6,25.5 ; P=0.027)$ for the first time in week 3 . After the peak in week 6 , volumes gradually decreased again, to $6.2 \%(95 \% \mathrm{Cl}:-0.2,12.6$; $P=0.058$ ) above pre-pandemic levels ${ }^{39}$ by around week 11 . When we

a

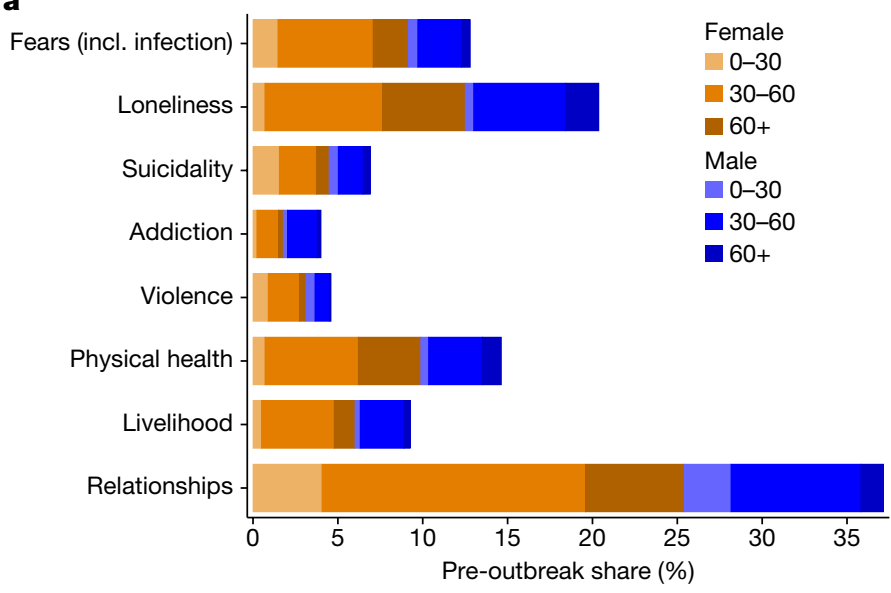

Fig. 2 | Conversation topics during the first COVID-19 wave. a, Pre-pandemic shares of main non-exclusive helpline conversation topics by sex and age group, before cumulative SARS-CoV-2 infections ${ }^{39}$ reached 1 per 100,000 population. b. Estimated coefficients for the binary post-outbreak indicator instead define the starting point of the pandemic as the entry into force of the first shelter-in-place (SIP) order $^{40}$, we observe an increase of $11.2 \%(95 \% \mathrm{Cl}: 3.1,19.4 ; P=0.007)$ (Fig. 1b) by week 2 , steadily elevated call volumes from week $3(+27 \%$; $95 \% \mathrm{Cl}: 19.1,35.0 ; P<0.001)$ until about week 8 (+22.6\%; 95\% CI: $15.2,30.1 ; P<0.001)$, and a decrease thereaf$\operatorname{ter}^{40}$. The different time profiles are mainly explained by the fact that on average, SIP orders were issued 2 to 3 weeks after local outbreaks (Extended Data Fig. 1, Extended Data Table 1).

The gradual nature of the increase in call volumes could, to some extent, be a result of capacity constraints ${ }^{4}$. Several helplines initially had to leave some of the additional calls unanswered and only gradually managed to adjust capacity to the new level of demand. Because of this issue, the evolution of recorded aggregate call numbers should be interpreted as a lower-bound estimate of the true increase in the number of people who sought to call a helpline in the first wave of the pandemic. However, unanswered calls are not pre-screened, and call answering is thus a random process unrelated to the motives of the caller. Thus our data provide representative information on the reasons for calling even if some calls were left unanswered because of capacity constraints.

\section{Caller issues and conversation topics}

We analysed the reasons for calling using data on the 12 helplines for which we have call-level information on conversation topics and caller characteristics. Our main results relating to call topics are presented in Fig. 2. Most pre-COVID-19 calls were made because of relationship issues (37\%), loneliness (20\%) or various fears and anxieties (13\%) (Fig. 2a). Women placed $61 \%$ of total calls, and $63 \%$ of calls were placed by people between 30 and 60 years of age. The breakdown by topic was fairly similar across helplines, with relationship issues being the most prevalent topic in 8 of the 10 helplines for which this category is defined (34\% overall) (Extended Data Fig. 2). More than $90 \%$ of 'calls' were voice calls, but for some helplines our data also includes text-based (online chat) conversations. Between $49 \%$ and $81 \%$ of calls were placed by first-time or sporadic callers, both before and after the onset of the pandemic (Extended Data Table 2).

During the first wave of the pandemic, defined here as lasting until the end of June 2020, the composition of calls changed significantly. The biggest increase in calls was recorded in the category 'fear', with 2.4 percentage points ( $95 \% \mathrm{Cl}: 1.8,2.9 ; P<0.001)$ (Fig. 2 b). This category includes calls made out of fear of infection with SARS-CoV-2. The other category of calls whose share increased during the first wave of the pandemic was 'loneliness' with 1.5 percentage points $(95 \% \mathrm{CI}$ :

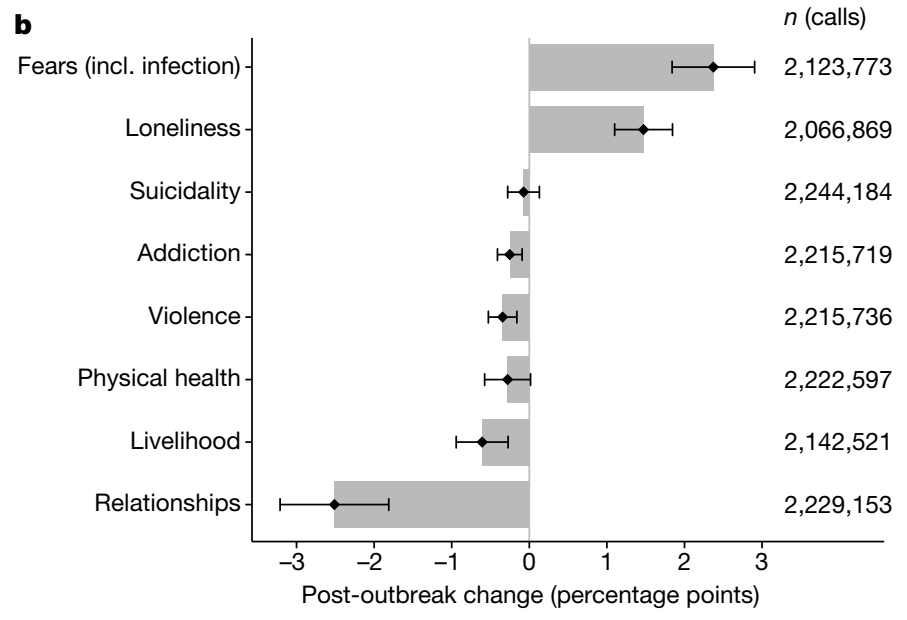

variable with $95 \%$ confidence intervals. Separate linear probability regression models with the dependent variable set to ' 1 ' for calls related to the indicated topic (Methods, equation (2)). 

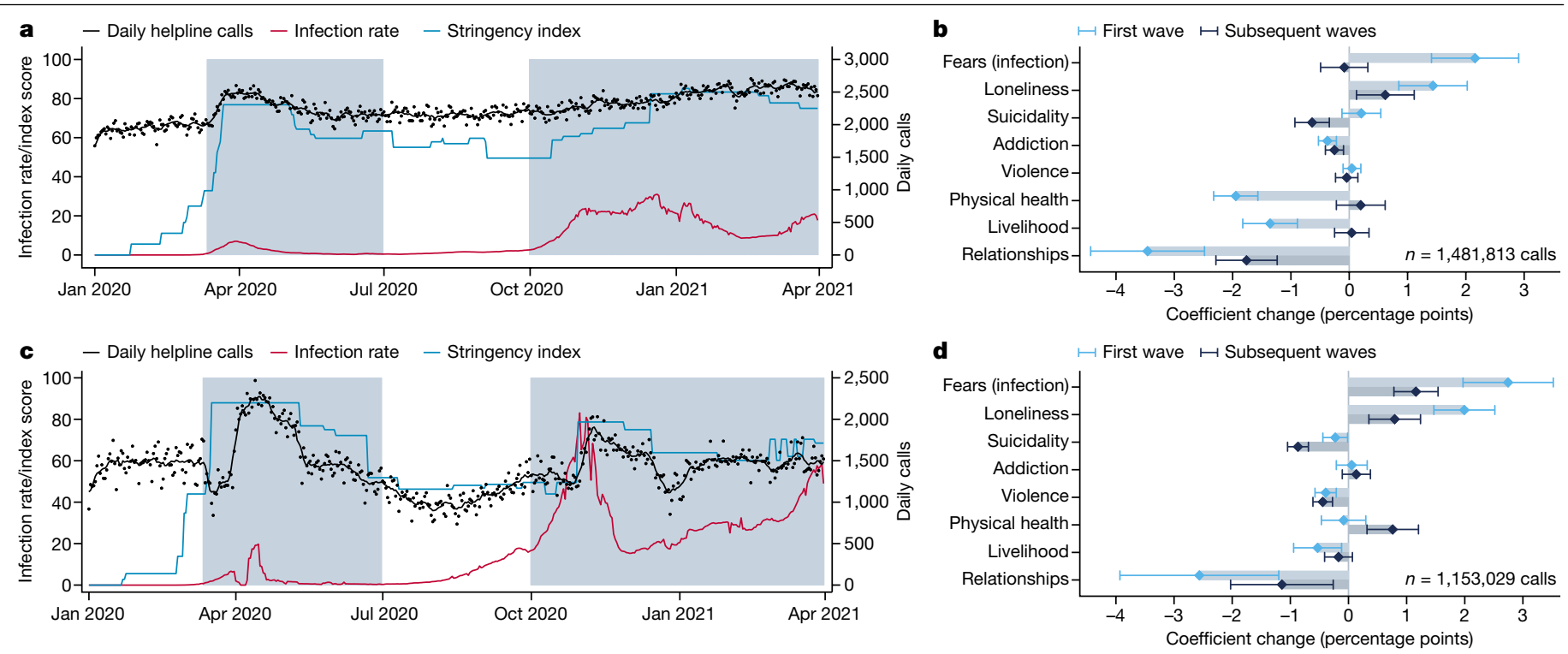

Fig. 3 | Helpline calls in Germany and France during the first and subsequent waves. a, c, Total number of daily helpline calls with seven-day moving average in black (right axis), government response stringency index in blue $^{40}$, and seven-day moving average of newly confirmed SARS-CoV-2 infections per 10,000 population and day in red (left axis) ${ }^{39}$, for Germany (Telefonseelsorge) (a) and France (SOS Amitié) (c). Shaded areas indicate first wave (11 March 2020-30 June 2020) and subsequent waves (1 October 2020-31 March 2021). b, d, Estimated coefficients for binary variables denoting the two periods, and their associated $95 \%$ confidence intervals for Germany (Telefonseelsorge) (b) and France (SOS Amitié) (d), based on separate linear probability regression models with the dependent variable set to ' 1 ' for calls related to the indicated topic (Methods, equation (4)).
1.1,1.8; $P<0.001$ ) (Fig. 2b). The share of all other conversation topics decreased during the first wave. Statistically significant relative decreases were observed for the topics 'relationships' ( -2.5 percentage points; $95 \% \mathrm{CI}:-3.2,-1.8 ; P<0.001$ ), 'livelihood' (that is, economic worries, -0.6 percentage points; $95 \% \mathrm{Cl}:-0.9,-0.3 ; P<0.00$ ), 'violence' ( -0.3 percentage points; $95 \% \mathrm{CI}:-0.5,-0.2 ; P<0.001)$ and 'addiction' ( -0.3 percentage points; $95 \% \mathrm{CI}:-0.4,-0.1 ; P=0.002$ ) (Fig. $2 \mathrm{~b}$ ). We detected no statistically significant change in the share of calls related to suicidal ideation ( -0.1 percentage points; $95 \% \mathrm{CI}:-0.3,-0.1$; $P=0.476$ (two-sided $t$-test of difference) and $P<0.006$ (two one-sided $t$-tests), against effect size $<-0.35$ and $>0.35$, respectively)) (Extended Data Fig. 3). These results show that the first wave of the pandemic and the associated measures led to a less than proportional increase in calls about domestic violence, addiction and suicidal ideation relative to the overall increase in calls.

When we break down post-pandemic changes in topic shares by gender and age group, we observe that the increase in fear-related calls was driven entirely by the over-30s, both male and female (between 2.1 and 3.1 percentage points; 95\% $\mathrm{Cl}: 1.5,2.7$ to $2.2,4.0 ; P<0.001$ ) (Extended Data Fig. 4). This is consistent with the fact that vulnerability to COVID19 increases monotonically with age. The share of suicide-related calls placed by men under 30 fell particularly strongly (by 1.6 percentage points; $95 \% \mathrm{Cl}:-2.3,-0.9 ; P<0.001$ ) (Extended Data Fig. 4). Conversely, the category of women under 30 stands out, with a 0.9 percentage points increase in the share of calls related to violence $(95 \% \mathrm{Cl}: 0.2,1.6$; $P=0.010$ ) (Extended Data Fig. 4), despite the fact that it may well have been more difficult under stay-at-home orders to make helpline calls in situations of domestic violence.

For around one-third of the calls underlying our analysis of Fig. 2, operators recorded more than one conversation topic (Extended Data Fig. 5a). In particular, calls related to 'violence' and 'livelihood' also concerned 'relationships' (39\% and 35\%, respectively) (Extended Data Fig. 5b), but combinations of all eight topics distinguished in our analyses were observed in the data. Dropping multiple-topic calls from the analysis left results almost unchanged (Extended Data Fig. 5c).
Overall, our results suggest that the observed increase in helpline calls during the first wave of the COVID-19 pandemic was driven to a large extent by fears of the virus itself and by loneliness in the context of SIP orders, rather than by domestic violence, addiction or suicidal ideation.

\section{Call dynamics during subsequent waves}

For two of the largest helplines in our sample, Telefonseelsorge (Germany) and SOS Amitié (France), we received data up to 31 March 2021, enabling us to analyse helpline calls beyond the first wave of the pandemic. Figure 3 shows that call volumes increased again in the second half of 2020, in parallel with an increase in infections and a tightening of non-pharmaceutical interventions (NPIs). Whereas in Germany the volume of calls increased continuously into early 2021 (Fig. 3a), in France it fell again after the peak in December 2020 (Fig. 3b). These diverging patterns correlate with stronger upswings and downswings in both infections and the stringency of government measures in the two countries.

Conversation topic patterns resemble each other both between the two helplines and between the two distinct periods of the pandemic. In Germany, calls due to loneliness increased by 1.4 percentage points (95\% CI: $0.9,2.0 ; P<0.016)$ in the first wave, and by 0.6 percentage points (95\% CI: $0.1,1.1 ; P<0.016)$ in subsequent waves (Fig. $3 b)$. In France, those increases were 2.0 percentage points $(95 \% \mathrm{CI}: 1.4$, $2.6 ; P<0.016)$ and 0.8 percentage points $(95 \% \mathrm{CI}: 0.4,1.2 ; P<0.001)$, respectively (Fig. 3b). During the first wave, the share of calls related to 'fear' (including the fear of infection) increased by 2.2 percentage points $(95 \% \mathrm{CI}: 1.4,2.9 ; P<0.001)$ in Germany, and by 2.7 percentage points (95\% Cl: 2.0, 3.5; $P<0.001)$ in France (Fig. 3b). For France, we also observed a significant increase during subsequent waves, by 1.2 percentage points ( $95 \% \mathrm{CI}: 0.8,1.5 ; P<0.001)$ (Fig. $3 \mathrm{~b})$. The share of calls concerning relationship issues decreased in Germany by 3.5 percentage points $(95 \% \mathrm{Cl}:-4.4,-2.5 ; P<0.001)$ in the first wave and by 1.8 percentage points $(95 \% \mathrm{Cl}:-2.3,-1.2 ; P<0.001)$ in subsequent waves (Fig. 3b). Decreases were also observed for France: -2.6 percentage points $(95 \% \mathrm{CI}:-3.9,-1.2 ; P<0.001)$ in the first wave, and 

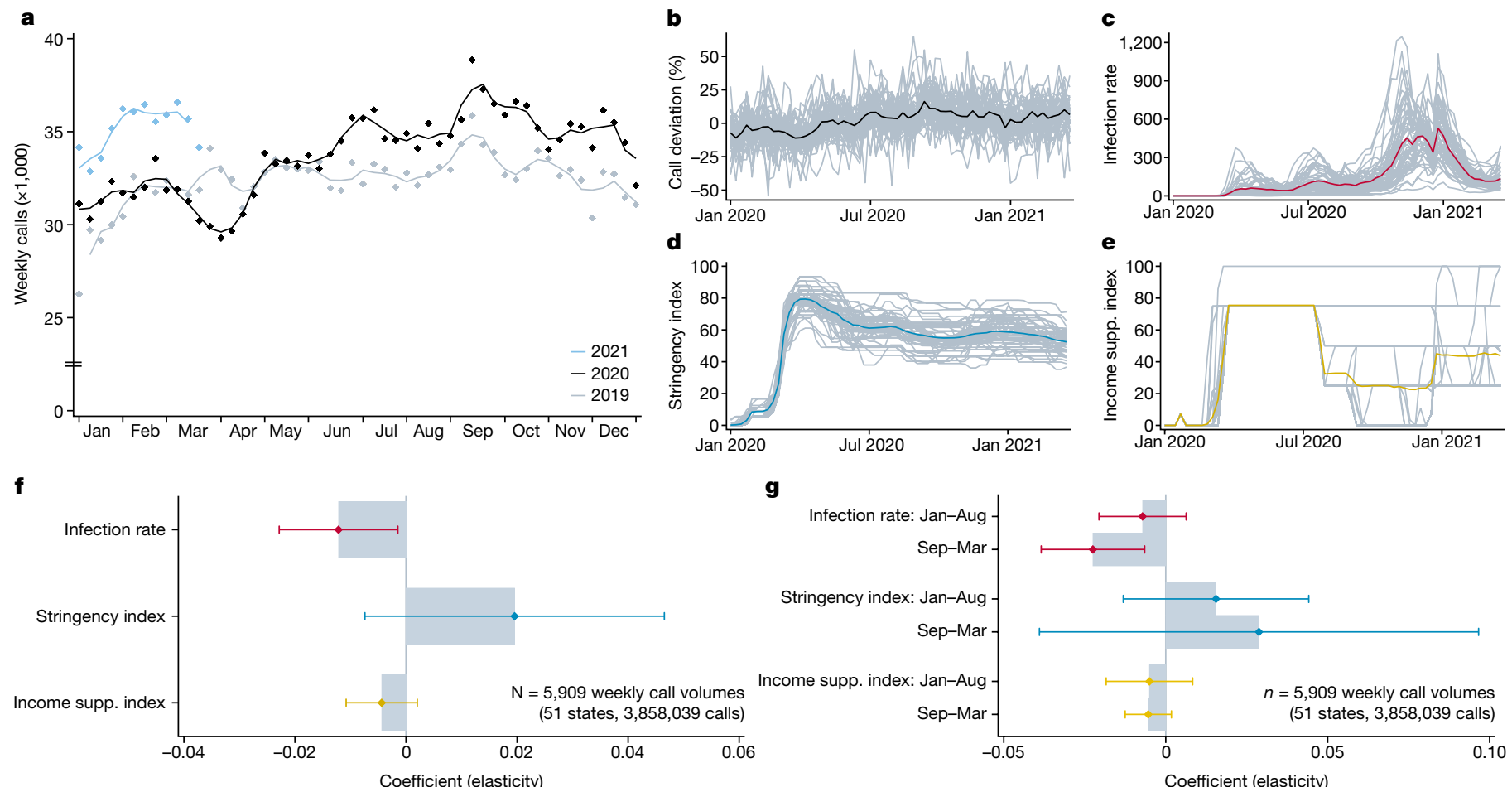

Fig. 4 | Lifeline calls, COVID-19 and policy measures in the USA. a, Total number of weekly calls routed to Lifeline centres by year, with three-week moving average (vertical axis is truncated). b, Deviation of logged calls from the time-averaged state-level mean (grey), with nationwide weekly average (black).c-e, Weekly average scores, with individual state values (grey).c, Newly confirmed SARS-CoV-2 infections ${ }^{39}$ per 100,000 population (mean in red). d, Government response stringency index (mean in blue). e, Income support index ${ }^{40}$ (mean in yellow).f, Estimated coefficients and associated $95 \%$ confidence intervals from sub-national panel model including state and week fixed effects. The dependent variable is $\ln$ (Lifeline calls +1 ) and natural log values of the independent variables are used (Methods, equation (5)). g, Coefficient estimates for interaction terms with indicators for the two periods from January to August 2020 and September 2020 to March 2021, and associated $95 \%$ confidence intervals (Methods, equation (6)).
-1.1 percentage points $(95 \% \mathrm{CI}:-2.0,-0.3 ; P<0.001)$ during the subsequent waves (Fig. 3b). Conversations were less likely to relate to suicidality during subsequent waves $(-0.6$ percentage points in Germany and -0.9 percentage points in France; $95 \% \mathrm{CI}:-0.9,-0.3$ and $-1.0,-0.7 ; P<0.001$ ) (Fig. 3b).

Conversely, a larger proportion of calls in the second and third waves in France concerned physical health ( +0.8 percentage points; $95 \% \mathrm{CI}$ : $0.3,1.2 ; P=0.001$ ) (Fig. 3b). This could be related to a larger share of the population being infected with SARS-CoV-2 or to health worries because of restricted or postponed access to treatment facilities and fewer opportunities for physical activity. Similar to the first wave, additional calls focused predominantly on issues linked directly with the pandemic: fear of infection, loneliness, and-new to subsequent waves-physical health.

\section{Infection rates and policy measures}

Helpline call data enable us to use panel data regression to isolate partial correlations between policy measures and indicators of mental health. A particularly informative empirical laboratory for this analysis are calls to the National Suicide Prevention Lifeline (hereafter referred to as Lifeline) in the USA. We have data for 2019, 2020 and early 2021, which enables us to exploit the considerable intranational (state-level) variation of epidemiological situations and policy measures observed within the USA. Thanks to coordination across the network of crisis centres that constitute the Lifeline through a common set of general guidelines, institutional and measurement issues that complicate comparisons across diverse sets of helplines and nations are less of a concern in this dataset. As a helpline focused on suicide, however, Lifeline does not enable us to track changes in the composition of mental health problems.
Our main findings are presented in Fig. 4. The aggregate time trend reveals that during the first wave, calls to Lifeline were no higher than in the corresponding period of 2019 (around 32,000 weekly calls) (Fig. 4a), but during subsequent waves they increased above pre-pandemic levels (more than 35,000 weekly calls in late 2020 and spring 2021). Figure $4 \mathrm{~b}$ illustrates the heterogeneity in the time profiles of calls across states that we seek to 'explain' with state-week variation in our three explanatory variables:SARS-CoV-2 infection rates ${ }^{39}$ (Fig. 4c), NPIs as measured by the components 'containment and closure policies' summarized in the stringency index (Fig. 4d), and the generosity of public compensation payments for labour costs (for example, furlough payments) as measured by the component 'income support' (Fig. 4e) in the Oxford COVID-19 Government Response Tracker ${ }^{40}$.

In Fig. 4f, we summarize our regression results based on data up to March 2021. For given policy measures, increases in SARS-CoV-2 infections were associated with statistically significant decreases in the number of calls to the suicide helpline (elasticity $=-0.012,95 \% \mathrm{Cl}$ : $-0.023,-0.001 ; P=0.026$ ) (Fig. 4f). The estimated coefficient implies that a $10 \%$ increase in SARS-CoV-2 infections is associated with a $0.1 \%$ reduction in calls to the suicide helpline.

One interpretation of this result is that the pandemic itself attenuates suicidal anxieties, perhaps by shifting people's focus towards the distress of others, or to their own fear of the pandemic. This interpretation is consistent with the evolution of calls to the US Disaster Distress Helpline, which was advertised for providing crisis counselling to people affected by COVID-19: calls to this helpline increased sharply during the initial phase of the pandemic (from around 500 to around 3,000 weekly calls) (Extended Data Fig. 6), suggesting some displacement of pre-existing anxieties by more proximate COVID-19-related sources of distress. 


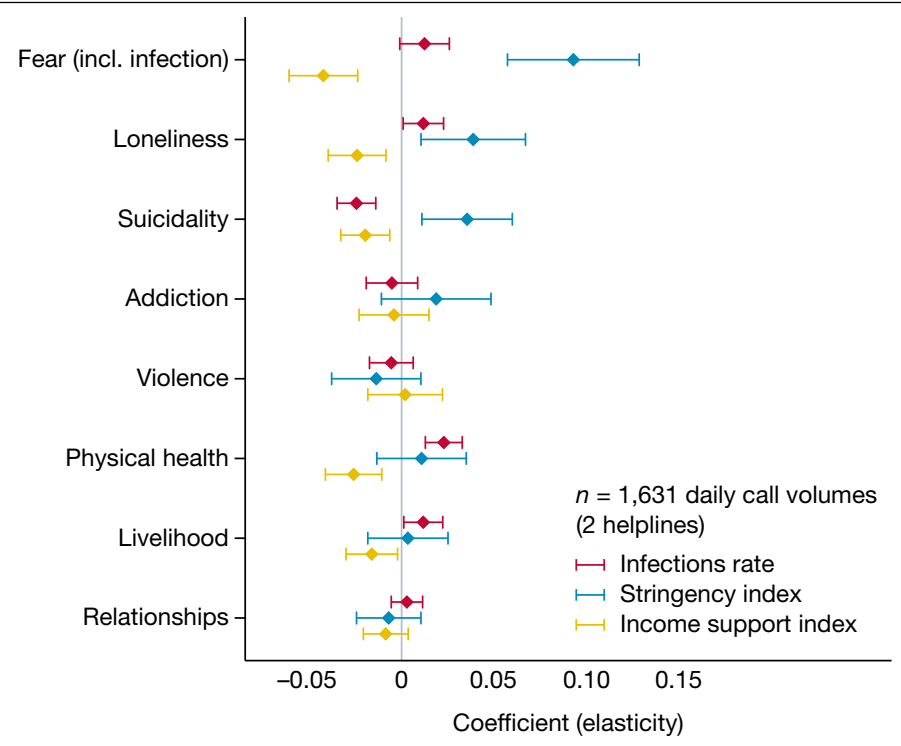

Fig. 5 | Daily calls by conversation topic, COVID-19, and policy in Germany and France. Coefficients from separate regression models by topic with $95 \%$ confidence intervals. The dependent variable is $\ln ($ Calls +1$)$, and natural $\log$ values of SARS-CoV-2 infections per 100,000 population ${ }^{39}$ and policy indices ${ }^{40}$ are used. The sample includes all calls to Telefonseelsorge (Germany) and SOS Amitié (France) for which at least one conversation topic was recorded, aggregated to daily totals from 1 January 2019 to 31 March 2021 (Methods, equation (7)).

Policy interventions in the shape of more stringent state-level NPIs or more generous state-level income support measures were not found to have statistically significant effects on Lifeline calls (effect of NPI stringency: 0.020; 95\% Cl: $-0.007,0.047 ; P=0.155$ ) (Fig. 4f). Even though the data do not have the statistical power to reject the hypothesis of no effect, our estimates are consistent with stricter NPIs being followed by an increase in Lifeline calls and with income support policies having the opposite effect.

Figure $4 \mathrm{~g}$ shows the estimated effects of the three explanatory variables separately for the first and subsequent waves of the pandemic, with the cut-off date placed at 1 September 2020. We find that the dampening effect on Lifeline calls of the pandemic itself (measured as the number of SARS-CoV-2 infections) increased over time ( -0.022 during the second sub-period; $95 \% \mathrm{Cl}$ : $-0.038,-0.006 ; P=0.006$ ) (Fig. $4 \mathrm{~g}$ ). The effects on Lifeline calls of more stringent NPIs or more generous income support, however, did not differ noticeably across waves of the pandemic. Together, these estimates confirm that the mental-health implications of the pandemic remained relatively stable across the first and subsequent waves. In Supplementary Tables 7, 8, we show that these qualitative results are robust across a range of panel regression specifications.

The pattern observed in US suicide helpline data is corroborated by a corresponding regression analysis based on the German and French helplines: all other things being equal, increasing SARS-CoV-2 infections and more generous income support policies were followed by falls in the number of helpline calls related to suicidality, with an elasticity of -0.024 (95\% Cl: $-0.035,-0.014 ; P<0.001)$ and -0.020 (95\% CI: -0.033 , -0.006; $P=0.004$ ), respectively (Fig. 5). Conversely, more stringent NPIs were followed by more suicide-related calls ( $+0.035,95 \% \mathrm{CI}: 0.011$, $0.060 ; P=0.005)$ (Fig. 5). These estimated effects are statistically significant and qualitatively consistent with those based on the Lifeline data.

Our findings suggest that public compensation payments for pandemic-induced losses not only reduce economic hardship but also have broader benefits: more generous income support leads to fewer calls due to fear $(-0.042 ; 95 \% \mathrm{Cl}:-0.061,-0.024 ; P<0.001)$, loneliness $(-0.024 ; 95 \% \mathrm{Cl}:-0.040,-0.008 ; P=0.003)$, physical health concerns
(-0.026; 95\% Cl: $-0.041,-0.011 ; P=0.001)$ and, as expected, economic anxiety ('livelihood'; $-0.016 ; 95 \% \mathrm{Cl}:-0.030,-0.002 ; P=0.023$ ) (Fig. 5).

\section{Discussion}

We drew on international helpline call data to shed light on a statistical blind spot of pandemic policy: mental health concerns and general distress of the population. Helpline calls increased during the pandemic, and this increase was driven primarily by concerns linked to the pandemic itself (such as fear of infection and loneliness). Conversely, on average, the share of calls due to other forms of distress, including suicidality, violence and addiction, decreased. The lack of an increase in the share of suicide-related calls is consistent with observed decreases in actual suicides during the early stages of the pandemic across several countries $^{28}$. Underlying these general patterns are helpline-specific evolutions that are documented in detail in Supplementary Figs.1-37.

The panel structure of the data enables us to estimate multivariate models to disentangle the separate effects of the pandemic itself (SARS-CoV-2 infections), of the stringency of containment policies, and of the generosity of income support policies. We found that more stringent measures were associated with a higher number of calls due to fear, loneliness and suicidality, but that more generous income support had the opposite effect. This implies that compensation payments to workers and businesses affected economically by COVID-19, which were designed to preserve demand and productive capacity, have additional benefits in alleviating distress and mental health concerns.

Longitudinal helpline data offer an attractive complement to existing empirical approaches based on surveys, administrative and clinical data (such as suicide statistics, admissions to treatment centres and so on), and internet search data. Helpline data also have their limitations. One such issue is that call counts may be influenced not only by demand but also by supply, as capacity constraints can force operators to leave some calls unanswered. This may cause a downward bias in measures of increases in demand. However, as calls are not pre-screened, capacity constraints are unlikely to affect analyses of the composition of calls in terms of topics or caller characteristics.

Another limitation lies in our agnosticism about the representativeness of callers to helplines. We are aware of no rigorous evidence regarding the composition of the helpline caller population in terms of socio-demographic status, health, occupation, nationality and other factors. By focusing our analysis on changes in call volumes over time, we eliminate time-invariant specificities of the helpline caller population, which should remove a large proportion of any potential sample selection bias. Moreover, anecdotal evidence from helpline workers confirms that the caller population typically includes the most vulnerable members of society, which is the population of greatest interest in a study of distress and mental health concerns.

\section{Online content}

Any methods, additional references, Nature Research reporting summaries, source data, extended data, supplementary information, acknowledgements, peer review information; details of author contributions and competing interests; and statements of data and code availability are available at https://doi.org/10.1038/s41586-021-04099-6.

1. COVID-19 and the Need for Action on Mental Health UN Sustainable Development Group Policy Brief (United Nations, 2020).

2. Tackling the Mental Health Impact of the COVID-19 Crisis: An Integrated, Whole-of-Society Response (OECD, 2021).

3. Rehm, J. \& Shield, K. D. Global burden of disease and the impact of mental and addictive disorders. Curr. Psychiatry Rep. 21, 10 (2019).

4. Batchelor, S., Stoyanov, S., Pirkis, J. \& Kõlves, K. Use of kids helpline by children and young people in Australia during the COVID-19 pandemic. J. Adolesc. Health 68, 1067-1074 (2021).

5. Zalsman, G. et al. Suicide-related calls to a national crisis chat hotline service during the COVID-19 pandemic and lockdown. J. Psychiatr. Res. 139, 193-196 (2021). 


\section{Article}

6. Turkington, R. et al. Behavior of callers to a crisis helpline before and during the COVID-19 pandemic: quantitative data analysis. JMIR Ment. Health 7, e22984 (2020).

7. Halford, E. A., Lake, A. M. \& Gould, M. S. Google searches for suicide and suicide risk factors in the early stages of the COVID-19 pandemic. PLoS ONE 15, e0236777 (2020).

8. Armbruster, S. \& Klotzbücher, V. Lost in lockdown? COVID-19, social distancing, and mental health in Germany. Covid Econ. 22, 117-153 (2020).

9. Brülhart, M. \& Lalive, R. Daily suffering: helpline calls during the COVID-19 crisis. Covid Econ. 19, 143-158 (2020).

10. Leach, L. S. \& Christensen, H. A systematic review of telephone-based interventions for mental disorders. J. Telemed. Telecare 12, 122-129 (2006).

11. Coveney, C. M., Pollock, K., Armstrong, S. \& Moore, J. Callers' experiences of contacting a national suicide prevention helpline. Crisis 33, 313-324(2012).

12. IFOTES Ethical Charter (IFOTES, 1993).

13. De Leo, D., Buono, M. D. \& Dwyer, J. Suicide among the elderly: the long-term impact of telephone support and assessment intervention in northern Italy. Br. J. Psychiatry 181, 226-229 (2002).

14. Choi, D. et al. Development of a machine learning model using multiple, heterogeneous data sources to estimate weekly US suicide fatalities. JAMA Netw. Open 3, e2030932 (2020).

15. Ridley, M., Rao, G., Schilbach, F. \& Patel, V. Poverty, depression, and anxiety: causal evidence and mechanisms. Science 370, eaay0214 (2020).

16. McInerney, M., Mellor, J. M. \& Nicholas, L. H. Recession depression: mental health effects of the 2008 stock market crash. J. Health Econ. 32, 1090-1104 (2013).

17. Parmar, D., Stavropoulou, C. \& loannidis, J. P. A. Health outcomes during the 2008 financial crisis in Europe: systematic literature review. BMJ 354, i4588 (2016).

18. Chang, S.-S., Stuckler, D., Yip, P. \& Gunnell, D. Impact of 2008 global economic crisis on suicide: time trend study in 54 countries. BMJ 347, f5239 (2013).

19. Phillips, J. A. \& Nugent, C. N. Suicide and the Great Recession of 2007-2009: the role of economic factors in the 50 US states. Soc. Sci. Med. 116, 22-31 (2014).

20. Nordt, C., Warnke, I., Seifritz, E. \& Kawohl, W. Modelling suicide and unemployment: a longitudinal analysis covering 63 countries, 2000-11. Lancet Psychiatry 2, 239-245 (2015).

21. Gunnell, D. et al. Suicide risk and prevention during the COVID-19 pandemic. Lancet Psychiatry 7, 468-471 (2020).

22. Zortea, T. C. et al. The impact of infectious disease-related public health emergencies on suicide, suicidal behavior, and suicidal thoughts. Crisis https://doi.org/10.1027/02275910/a000753 (2020).

23. Richter, D., Riedel-Heller, S. \& Zürcher, S. Mental health problems in the general population during and after the first lockdown phase due to the SARS-Cov-2 pandemic: rapid review of multi-wave studies. Epidemiol. Psychiatr. Sci. 30, E27 (2021).

24. Banks, J., et al. The mental health effects of the first two months of lockdown during the COVID-19 pandemic in the UK. Fisc. Stud. 41, 685-708 (2020).
25. Holman, E. A., Thompson, R. R., Garfin, D. R. \& Silver, R. C. The unfolding COVID-19 pandemic: a probability-based, nationally representative study of mental health in the United States. Sci. Adv. 6, eabd5390 (2020)

26. Holingue, C. et al. Mental distress during the COVID-19 pandemic among US adults without a preexisting mental health condition: Findings from American trend panel survey. Prev. Med. 139 (2020)

27. John, A., Pirkis, J., Gunnell, D., Appleby, L. \& Morrissey, J. Trends in suicide during the COVID-19 pandemic. BMJ 371, m4352 (2020).

28. Pirkis, J. et al. Suicide trends in the early months of the COVID-19 pandemic: Interrupted time series analysis of preliminary data from 21 countries. Lancet Psychiatry 8, 579-588 (2021).

29. Tanaka, T. \& Okamoto, S. Increase in suicide following an initial decline during the COVID-19 pandemic in Japan. Nat. Hum. Behav. 5, 229-238 (2021).

30. Berger, L. M., Ferrari, G., Leturcq, M., Panico, L. \& Solaz, A. COVID-19 lockdowns and demographically relevant Google Trends: a cross-national analysis. PLoS ONE 16, e0248072 (2021)

31. Brodeur, A., Clark, A. E., Fleche, S. \& Powdthavee, N. COVID-19, lockdowns and well-being: evidence from Google Trends. J. Public Econ. 193, 104346 (2020).

32. Silverio-Murillo, A., Hoehn-Velasco, L., Tirado, A. R. \& de la Miyar, J. R. B. COVID-19 blues: lockdowns and mental health-related Google searches in Latin America. Soc. Sci. Med. 281, 114040 (2021)

33. Fetzer, T., Hensel, L., Hermle, J. \& Roth, C. Coronavirus perceptions and economic anxiety. Rev. Econ. Stat. https://doi.org/10.1162/rest_a_00946 (2020).

34. Faust, J. S. et al. Suicide deaths during the COVID-19 stay-at-home advisory in Massachusetts, March to May 2020. JAMA Netw. Open 4, e2034273 (2021)

35. Holland, K. M. et al. Trends in US emergency department visits for mental health, overdose, and violence outcomes before and during the COVID-19 pandemic. JAMA Psychiatry 78, 372-379 (2021).

36. Baron, E. J., Goldstein, E. G. \& Wallace, C. T. Suffering in silence: how COVID-19 school closures inhibit the reporting of child maltreatment. J. Public Econ. 190, 1-13 (2020).

37. Bullinger, L. R., Carr, J. B. \& Packham, A. COVID-19 and crime: effects of stay-at-home orders on domestic violence. Am. J. Health Econ. 7, 249-280 (2021).

38. Leslie, E. \& Wilson, R. Sheltering in place and domestic violence: evidence from calls for service during COVID-19. J. Public Econ. 189, 104241 (2020).

39. Dong, E., Du, H. \& Gardner, L. An interactive web-based dashboard to track COVID-19 in real time. Lancet Infect. Dis. 20, 533-534 (2020).

40. Hale, T. et al. A global panel database of pandemic policies (Oxford COVID-19 Government Response Tracker). Nat. Hum. Behav. 5, 529-538 (2021).

Publisher's note Springer Nature remains neutral with regard to jurisdictional claims in published maps and institutional affiliations.

(C) The Author(s), under exclusive licence to Springer Nature Limited 2021 


\section{Methods}

\section{Helpline call data}

Our sample of helplines includes large general crisis helplines and dedicated suicide prevention helplines, as well as some helplines that focus on specific groups such as children, parents or immigrants. Observations within helplines are self-selected, as they consist of callers to helplines. The selection of sample helplines was based on (1) an internet search of well-documented helplines, and (2) receiving data from those helplines. Out of 154 helplines that we contacted, we received data from 37 helplines. Where possible, we requested data from 1 January 2019 to the most recent available date, to enable a comparison of call patterns after the COVID-19 outbreak with call patterns at the same time of year before the pandemic. The information obtained from 23 helplines was of sufficiently detailed coverage and consistency to be included in our pooled analyses. Extended Data Table 1 lists the included helplines, grouped by the format in which the data were made available for this study.

The most detailed information was provided by the helplines in Extended Data Table 1a, where we received individual conversation-level data, including information on the callers' sex and approximate age, as well as on the issues discussed during the conversation. From the three additional helplines in Extended Data Table 1b, we received aggregate time series of daily call volumes, with separate series by gender, age category and topic. Moreover, for the two helplines in Extended Data Table 1c, we received sub-national weekly series of call volumes across US states. In contrast to the data from helplines in Extended Data Table 1a, b, the number of calls in Extended Data Table 1c does not refer to answered calls and actual conversations, but to the raw number of calls routed to local centres.

Data processing and analysis were conducted according to the guidelines of the Internal Review Board (IRB) of the Faculty of Business and Economics at the University of Lausanne. Two considerations were important. First, all helplines guarantee anonymity to their callers, both towards their operators and towards the outside world. Names and addresses are never asked for, and caller numbers are hidden by the system. It is therefore impossible to identify callers even from the call-level data provided by a subset of helplines, and the anonymous information is not covered by data protection considerations. Second, all of the helplines we analysed inform callers that anonymous call data are collected for reporting and statistical purposes, whether explicitly in the terms and conditions or statutes, and/or implicitly in annual reports and online publications. The analysis of those data conforms with the aim of the Ethics Charter of the International Federation of Telephone Emergency Services (IFOTES), which aims to “(c)ollect and disseminate data gathered by the Branches in connection with the challenges facing Mental Health and Prevention of Suicide" and to “(a)ssist and encourage research carried out in these fields"12. The IRB exempted the study from a full review owing to the secondary nature of the data used.

\section{Government response and epidemiological data}

To measure the timing and intensity of government responses consistently across time, countries and sub-national regions, we rely on aggregate policy indices from the Oxford COVID-19 Government Response Tracker $^{40}$. In particular, we use two policy indices, the government response stringency index and the income support index. The stringency index shows the strictness of containment policies and restrictions of personal freedom, and is based on an unweighted average of eight component scores for shelter-in-place requirements, workplace and public transport closures, restrictions on public events, gatherings, domestic and international travel, and information campaigns. The income support index reflects the availability of financial support and is constructed the index score using the ordinal measure and the flag for sectoral targeting to arrive at a value between 0 and 100 (following the definition of the stringency index). For the sub-national information on policies in US states, it is important to note that we use the total index scores, where, whenever national policies were more restrictive than those of individual states, the higher score is imputed. Data on the daily number of newly confirmed SARS-CoV-2 infections are taken from the JHU CSSE COVID-19 Dataset ${ }^{39}$.

\section{Call volumes after the pandemic outbreak}

For Fig. 1, we combine the time-series data (Extended Data Table 1b) with aggregates based on the call-level data (Extended Data Table 1a) in a panel of daily call volumes for 21 helplines, covering the time up to 30 June 2020 if available. For four of the helplines (MIELI, SOS Détresse, Sahar and Muslimisches Seelsorgetelefon), no data were available for 2019. We then look exclusively on the period from 4 weeks before to 12 weeks after the country-specific event date in 2020 , as well as, if available, the corresponding days in 2019. To summarize the overall dynamics, we estimate the following model:

$$
\ln \left(\text { Calls }_{h, t}\right)=\sum_{\tau=-4}^{-1} \gamma^{\tau} \text { Week }_{h, t}^{\tau}+\sum_{\tau=1}^{12} \gamma^{\tau} \text { Week }_{h, t}^{\tau}+\xi_{h} \times \mathbf{\theta}_{t}+\epsilon_{h, t}
$$

The dependent variable is the natural logarithm of the number of calls to helpline $h$ recorded on day $t$. We define the local outbreak as the date when (1) the cumulative number of SARS-CoV-2 infections in the population exceeded $1 / 100,000$ or (2) when SIP orders were first introduced. For both versions, we define indicator variable Week ${ }^{\tau}$, which is set ' 1 ' for days in event week number $\tau$ in 2020 . The model includes helpline fixed effects $\xi_{h}$ interacted with year, week-of-year and day-of-week indicators, summarized in the vector $\boldsymbol{\Theta}_{t}$. The reference category is week 0 of the pandemic outbreak or SIP introduction, and the coefficient $\gamma^{\tau}$ allows us to track the percentage deviation in daily calls, controlling for seasonal effects and secular trends. See Supplementary Table 1 and Extended Data Fig. 1 for details on event dates and call volumes for each of the 21 included helplines. Supplementary Table 2 contains numerical estimation results.

\section{Helpline data on individual calls}

To investigate changes in conversation topics (Fig. 2), we focus on the call-level data and combine information from 12 helplines (Extended Data Table 1a) for which we have information on conversation topics and inferred caller characteristics. This yields a sample of up to 2.2 million calls. For each helpline, we categorize calls on the basis of the recorded information on the problems of callers and the topics discussed. Precise categorizations of call topics differ across helplines, but they are sufficiently similar to allow us to map them into to the following common, non-exclusive categories: loneliness (social isolation, entrapment), fear (general fear, anxiety disorder, fear of infection with SARS-Cov-2), suicidality (suicidal ideation, suicidal thoughts or plans, suicide attempts, suicidality of others), addiction (drugs, alcohol, other addictions), violence (physical violence and abuse, sexual harassment, rape), physical health (disease, long-term illness, disability), and two broad categories for livelihood (work situation, unemployment, financial problems, housing), and relationships (family life, parenting, marriage and intimate relationships, separation). Supplementary Tables 12-22 show the precise topic definitions for each helpline. As some topics are not recorded at all for some helplines, the sample size differs depending on which topic we look at: the largest sample includes data from 12 helplines, where we can distinguish calls related to suicide from calls concerning other issues (Extended Data Fig. 2). Recorded conversation topics can be non-exclusive. We document the joint distribution of topics in Extended Data Fig. 5a.

Additionally, we have coded the sex and age category of each caller, and (where possible) further characteristics such as marital status, living situation and occupational status. As helplines record age categories differently, our classification cannot be fully precise. Using the boundaries of available age groups, the group of callers below 30 
includes only those that were recorded in an age group with an upper limit at or below 30 . The same logic applies to the group of callers older than 60 , and the middle category in some cases includes also individuals whose age is slightly below 30 years or above 60 .

For Fig. 2, we restrict the sample to calls recorded for the time from 1 January 2019 through 30 June 2020, where information on sex and age group of callers is available. When estimating the relative importance of a topic, we define the dependent variable $T$ as equal to ' 1 ' for call $i$ to helpline $h$ on day $t$ if the conversation was related to the respective topic (Fear, Loneliness, Suicide, Addiction, Violence, Physical health, Livelihood, or Relationships), and zero for unrelated calls, where another topic was recorded. Calls without information on caller issues or conversation topics are not included. Based on the date when the cumulative number of SARS-CoV-2 infections per population exceeded $1 / 100,000$ in the country of operation ${ }^{39}$, we define an indicator 'Post outbreak' and estimate a linear probability model as in equation (2):

$$
T_{i, h, t}=\gamma \text { Post outbreak }_{h, t}+\xi_{h} \times \Theta_{t}+\epsilon_{i, h, t}
$$

The model includes the helpline indicator $\xi_{h}$ to account for time-invariant differences among helplines. We further add year, week-of-year and day-of-week indicators, summarized in the vector $\boldsymbol{\Theta}_{t}$, interacted with the helpline fixed effects, to account for secular trends and for seasonal and day-of-week effects. Standard errors are clustered at the helpline-week level. Supplementary Table 3 contains numerical estimation results.

For the analysis of heterogeneous effects in Extended Data Fig. 4, we estimate an alternative specification including individual caller characteristics and interaction terms. To illustrate the change in topics for different groups, we classify callers into six non-overlapping groups, denoted in the vectors Sex (male, female) and Age group (below 30, 30-60, above 60). In the model illustrated in equation (3), we interact the post-outbreak variable Post with all six group indicators, so that the coefficients represent the group-specific changes in topic shares:

$$
\begin{aligned}
T_{i, h, t}= & \beta\left(\text { Sex }_{i, t} \times \text { Age group }_{i, t}\right)+\gamma \operatorname{Post}_{h, t}\left(\text { Sex }_{i, t} \times \text { Age group }_{i, t}\right) \\
& +\xi_{h} \times \boldsymbol{\Theta}_{t}+\epsilon_{i, h, t}
\end{aligned}
$$

For the main effects of caller sex and age groups, indicators for the reference group of male callers in the 30-60 age category are omitted. Supplementary Table 4 contains numerical estimation results.

For the analysis of the longer time horizon and subsequent waves in Fig. 3, we focus on call-level data from Germany and France, from 1 January 2019 to 31 March 2021. We estimate a specification similar to the previous approach, separately for the two helplines and each topic. To distinguish the changes around the outbreak from later adjustments during the subsequent wave, we define two indicator variables W1 and W2 denoting two periods. The first covers the time from 11 March 2020 , when the World Health Organization declared the outbreak a pandemic, to 30 June 2020, when the number of infections decreased again and containment measures were relaxed both in Germany and in France. The second period indicator is equal to one for the time after 10 ctober 2020. Equation (4) illustrates the estimated model:

$$
T_{i, h, t}=\gamma_{1} \mathrm{~W} 1_{h, t}+\gamma_{2} \mathrm{~W} 2_{h, t}+\boldsymbol{\Theta}_{t}+\epsilon_{i, h, t}
$$

As we analyse the two helplines separately, we do not include helpline fixed effects here, but capture secular trends and seasonal patterns through the inclusion of year, week-of-year, and day-of-week indicators summarized in the vector $\boldsymbol{\Theta}_{t}$. Standard errors are clustered at the week level. See Supplementary Table 6 for numerical estimation results.

\section{Call volumes across US states}

The analysis of sub-national call volumes in Fig. 4 relies on data on weekly call volumes routed to Lifeline. The analysis is based on weekly call volumes for US states and territories over 116 weeks, starting in the week to 6January 2019, and up to the week ending on Sunday, 21 March 2020 (Supplementary Fig. 37). Based on phone numbers, the state from which calls were placed can be inferred, even though internal migration means that this classification is subject to measurement error. While the Lifeline will serve any calls regardless of country of origin, its mission is to serve calls originating from the US and US territories. We focus on calls from 50 US states and DC. Calls originating from Canadian provinces, US territories, as well as those of other international or unknown origin are not considered, to maximize consistency and because of the limited availability of data on policy responses. The panel structure allows us to exploit the idiosyncratic variation within states jover time (weeks $w$ ) while controlling for overall trends. We estimate a two-way error component model as illustrated in equation (5):

$$
\begin{aligned}
\ln \left(\text { Calls }_{j, w}+1\right)= & \Pi_{1} \ln \left(\text { Infections }_{j, w}+1\right)+\Pi_{2} \ln \left(\text { Stringency }_{j, w}+1\right) \\
& +\Pi_{3} \ln \left(\text { Income support }_{j, w}+1\right)+\xi_{j}+\theta_{w}+\epsilon_{j, w}
\end{aligned}
$$

The dependent variable is the natural logarithm of the number of calls plus one, Infections is defined as one plus the sum of newly confirmed SARS-CoV- 2 infections in week $w$ per 100,000 population, while stringency and income support are calculated as weekly averages of the respective daily index scores. State fixed effects $\xi_{j}$ absorb all time-invariant factors, and our analysis is therefore based on the idiosyncratic within-state variation in call volumes over time. The inclusion of week indicators $\theta_{w}$ allows us to capture all nation-wide and global effects and to focus solely on the relative differences in pandemic exposure and policy response. Standard errors are clustered at the state-month level.

To investigate the extent to which the relationship changed over time, we re-estimate the model as in equation (6). Here, we include the three main explanatory variables, interacted with two indicator variables that are set to " 1 " for the time period from 1 January to 31 August 2020, and for 1September 2020 to 21 March 2021, respectively. Supplementary Tables 7,8 contain numerical estimation results from alternative specifications.

$$
\begin{aligned}
& \ln \left(\text { Calls }_{j, w}+1\right)=(\text { Jan }- \text { Aug })_{w}\left[\phi_{1} \ln \left(\text { Infections }_{j, w}+1\right)\right. \\
& +\phi_{2} \ln \left(\text { Stringency }_{j, w}+1\right) \\
& \left.+\phi_{3} \ln \left(\text { Income support }_{j, w}+1\right)\right] \\
& +(\text { Sep }- \text { Mar })_{w}\left[\psi_{1} \ln \left(\text { Infections }_{j, w}+1\right)\right. \\
& +\psi_{2} \ln \left(\text { Stringency }{ }_{j, w}+1\right)+\psi_{3} \\
& \left.\ln \text { (Incomesupport }{ }_{j, w}+1\right) \text { ] } \\
& +\xi_{j}+\theta_{w}+\epsilon_{j, w}
\end{aligned}
$$

\section{Call volumes in Germany and France}

For the analysis in Fig. 5, we combine the previous approaches and estimate the relationship between call volumes and the three variables as illustrated in equation (7), based on topic-specific call volumes to Telefonseelsorge (Germany) and SOS Amitié (France) during the time from 1 January 2019 to 31 March 2021.

$$
\begin{aligned}
\ln \left(\text { Calls }_{h, t}+1\right)= & \Pi_{1} \ln \left(\text { Infections }_{h, t}+1\right)+\Pi_{2} \ln \left(\text { Stringency }_{h, t}+1\right) \\
& +\pi_{3} \ln \left(\text { Income support }_{h, t}+1\right)+\xi_{h} \times \boldsymbol{\Theta}_{t}+\epsilon_{h, t}
\end{aligned}
$$

In contrast to the sub-national panel of US states, here we do not include week fixed effects but capture secular trends and seasonal 
patterns through helpline fixed effects $\xi_{h}$, interacted with year, week-of-year and day-of-week indicators summarized in the vector $\boldsymbol{\Theta}_{t}$. Standard errors are clustered at the helpline-week level. Numerical estimation results are shown in Supplementary Table 9.

\section{Reporting summary}

Further information on research design is available in the Nature Research Reporting Summary linked to this paper.

\section{Data availability}

Data were provided by helplines for the sole purpose of this research project, subject to confidentiality agreements. The full data underlying specific parts of the analysis are available from the authors upon reasonable request and conditional on permission of the respective helplines. To obtain (updated) helpline data, researchers have to sign agreements with individual helplines-for further information, contact: presse@telefonseelsorge.de(Telefonseelsorge,Germany),contact@ sosamitieparisidf.fr (SOS Amitié), info@deluisterlijn.nl (De Luisterlijn),info@nummergegenkummer.de (Nummer gegen Kummer),federatie@tele-onthaal.be (Tele-Onthaal),telefonseelsorge@edw.or.at (Telefonseelsorge, Austria), Icicenter@163.com (Hope Line), telefonoamico@telefonoamico.it (Telefono Amico),samarijan@gmail.com (Zaupni Telefon Samarijan),hana.regnerova@modralinka.cz (Modrá linka),support@sahar.org.il(Sahar),direccaolphm@gmail.com(SOS VozAmiga),info@mutes.de (MuslimischesSeelsorgetelefon),info@ embracelebanon.org (Embrace Lifeline),info@sosdetresse.lu (SOS Détresse),info@novageneracija.org(Plavi Telefon),sbhkinfo@sbhk. org.hk (Samaritan Befrienders),verband@143.ch (Die Dargebotene Hand),sos-keskus@mieli.fi (MIELI),lesziroda@gmail.com (LESZ) and info@vibrant.org (Lifeline and Disaster Distress Helpline). Data on infection rates and policy measures are publicly available online from the JHU CSSE COVID-19 Dataset at https://github.com/CSSEGISandData and the Oxford COVID-19 Government Response Tracker at https:// github.com/OxCGRT. Source data are provided with this paper.

\section{Code availability}

Files were collected in MS Excel 2016 and Notepad++v7.9.5. Data preparation and analysis was carried out in Stata/SE17.0, Do-files are available online at https://doi.org/10.5281/zenodo.5495830.

Acknowledgements We thank the following people and helplines for sharing their expertise and for granting us access to their data: C. Hochhauser and A. Kesselring (Telefonseelsorge, Austria), J. Pots (Tele-Onthaal, Belgium), M. Kovacevic (Plavi Telefon, Bosnia and Herzegovina), R. Ma and W. Ni (Hope Line, China), H. Regnerova (Modrá linka, Czech Republic), H. Dumont (SOS Amitié, France), S. Winter (MIELI, Finland), L. Storch and B. Blömeke (Telefonseelsorge, Germany), M. I. Sagir (Muslimisches Seelsorgetelefon, Germany), H. Schütz (Nummer gegen Kummer, Germany), H.-Chia (Samaritan Befrienders, Hong Kong), E. Brandisz (LESZ, Hungary), Y. Levy (Sahar, Israel), M. Petra (Telefono Amico, Italy), P. Zeinoun (Embrace Lifeline, Lebanon), S. Hay (SOS Détresse, Luxembourg), J. Jakobs (De Luisterlijn, Netherlands), F. Paulino (SOS Voz Amiga, Portugal), K. Bogataj (Zaupni telefon Samarijan, Slovenia), S. Basler (Die Dargebotene Hand, Switzerland), A. Goldstein, J. Higgins, S. Murphy and J. Draper, Vibrant Emotional Health (National Suicide Prevention Lifeline and Disaster Distress Helpline, USA). We thank C. Efferson, E. Fehr, L. Keller, K. Kõlves, J. Vornberger and S. Métille for comments and suggestions. We are grateful to the Swiss National Science Foundation (NCCR LIVES-'Overcoming Vulnerability: Life Course Perspectives') for financial support.

Author contributions S.K.R., V.K., M.B. and R.L. collected data. R.L., M.B., V.K. and S.K.R. designed the empirical approach. V.K., M.B. and R.L. implemented the analysis. M.B., V.K., R.L. and S.K.R. wrote the paper.

Competing interests The authors declare no competing interests.

\section{Additional information}

Supplementary information The online version contains supplementary material available at https://doi.org/10.1038/s41586-021-04099-6.

Correspondence and requests for materials should be addressed to Marius Brülhart. Peer review information Nature thanks Lola Kola, Kairi Kolves and the other, anonymous, reviewer(s) for their contribution to the peer review of this work. Peer reviewer reports are available.

Reprints and permissions information is available at http://www.nature.com/reprints. 

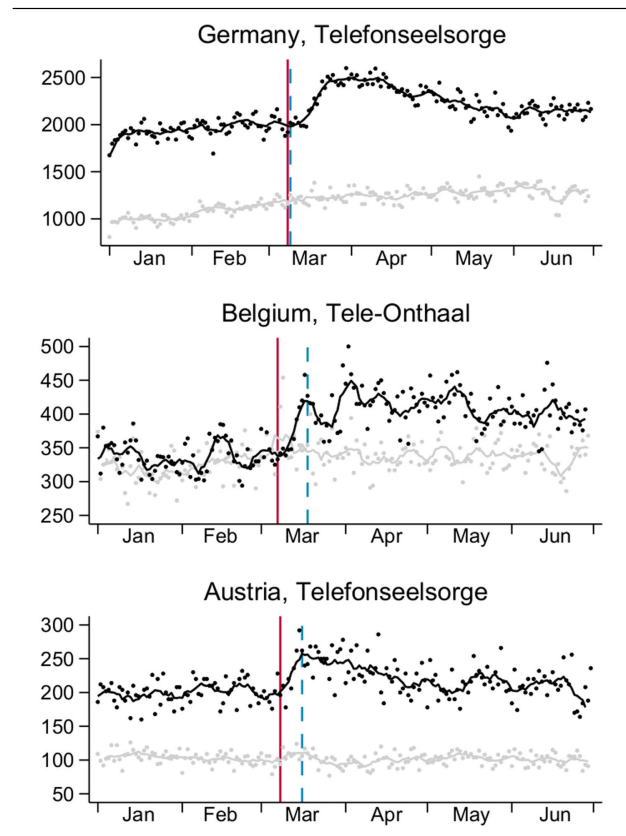

China, Hope line

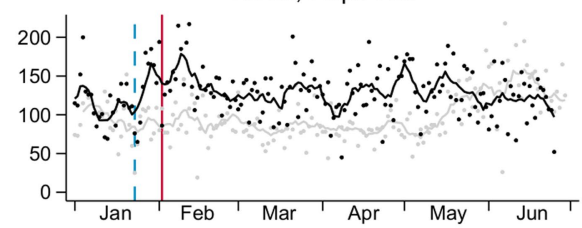

Germany, Nr. gegen Kummer (parents)

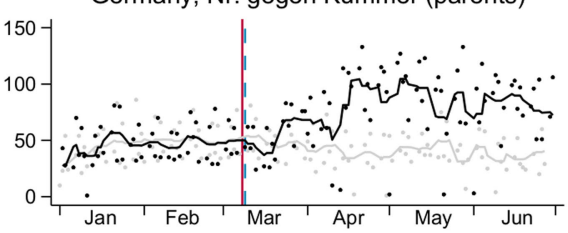

Portugal, S.O.S. Voz Amiga

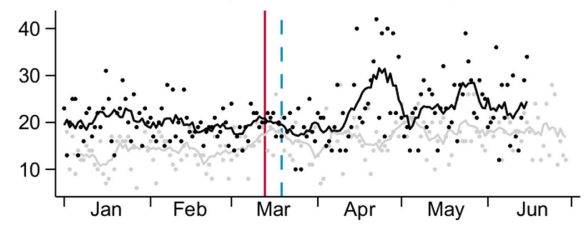

Luxembourg, SOS Détresse

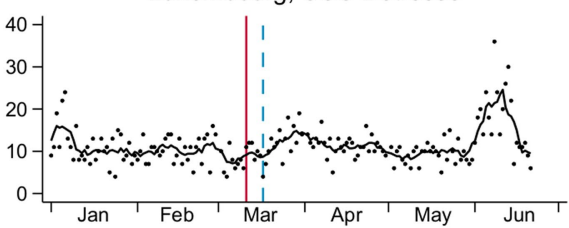

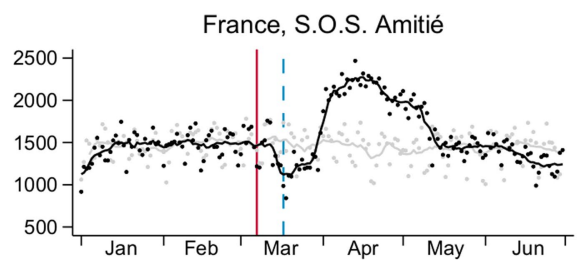

Switzerland, Die Dargebotene Hand

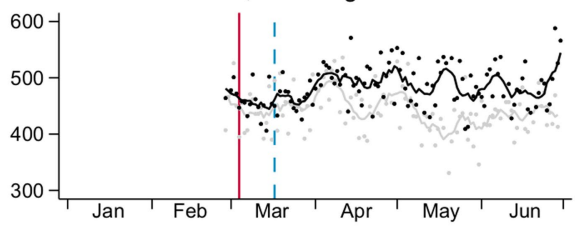

Hungary, LESZ

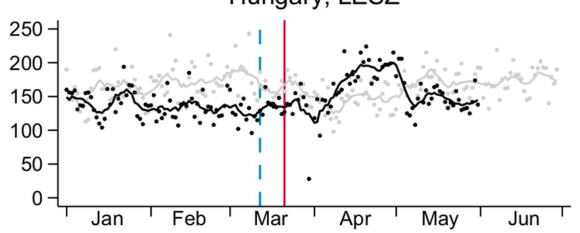

Finland, MIELI Mental Health

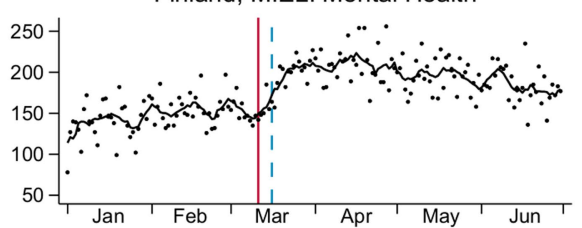

Czech Republic, Modrá linka

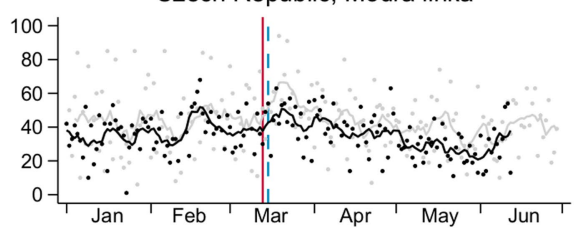

Lebanon, Embrace

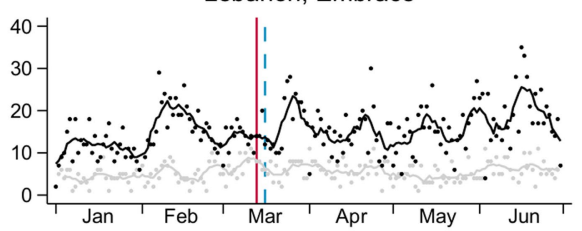

Hong Kong, Samaritan Befrienders

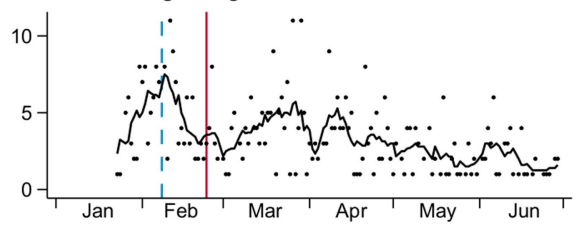

Netherlands, De Luisterlijn

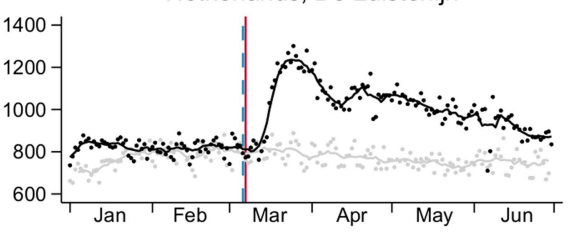

Germany, Nr. gegen Kummer (children)

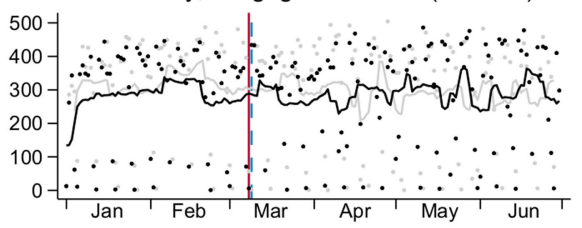

Italy, Telefono Amico

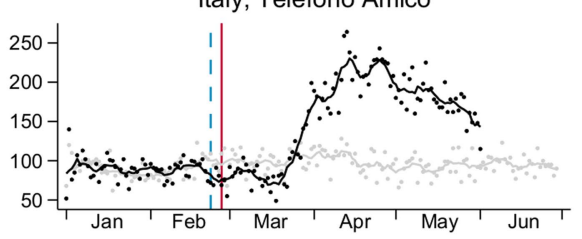

Slovenia, Zaupni telefon Samarijan

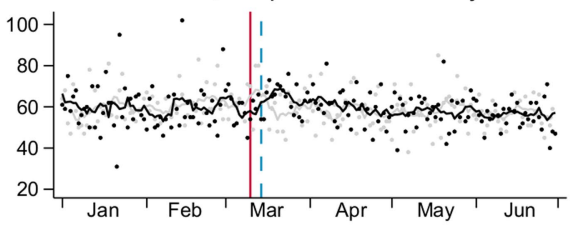

Israel, SAHAR Emotional support chat

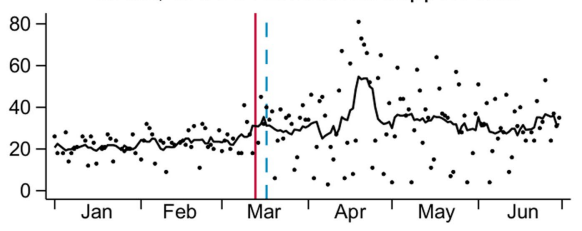

Germany, Muslimisches Seelsorgetelefon

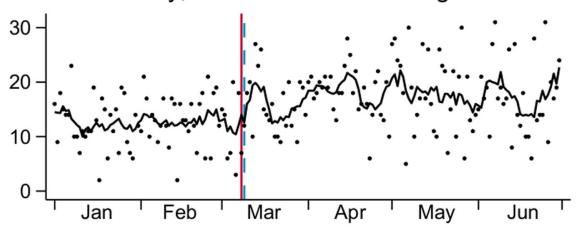

Bosnia, Plavi Telefon

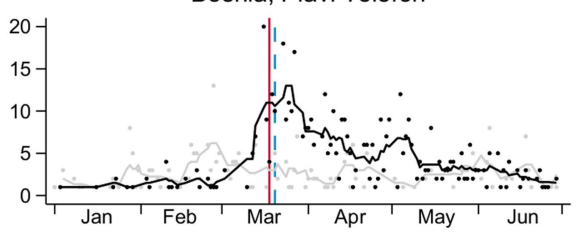

Extended Data Fig. 1 | Evolution of daily helpline call volumes during the first wave. Sum of daily helpline contacts with seven-day moving average, January-June 2020 (black) and 2019 (light grey, not available for all helplines). Note that the vertical axes are truncated and not equal across panels, and the magnitudes of changes are thus not directly comparable. The solid red line shows the date of the pandemic outbreak, when more than 100 SARS-CoV-2 infections per 100,000 population have been recorded ${ }^{39}$, the dashed blue line shows the date when shelter-in-place requirements were first introduced in the country of operation ${ }^{40}$, see Supplementary Figs. 1-34 for details on individual helplines. 


\section{N}

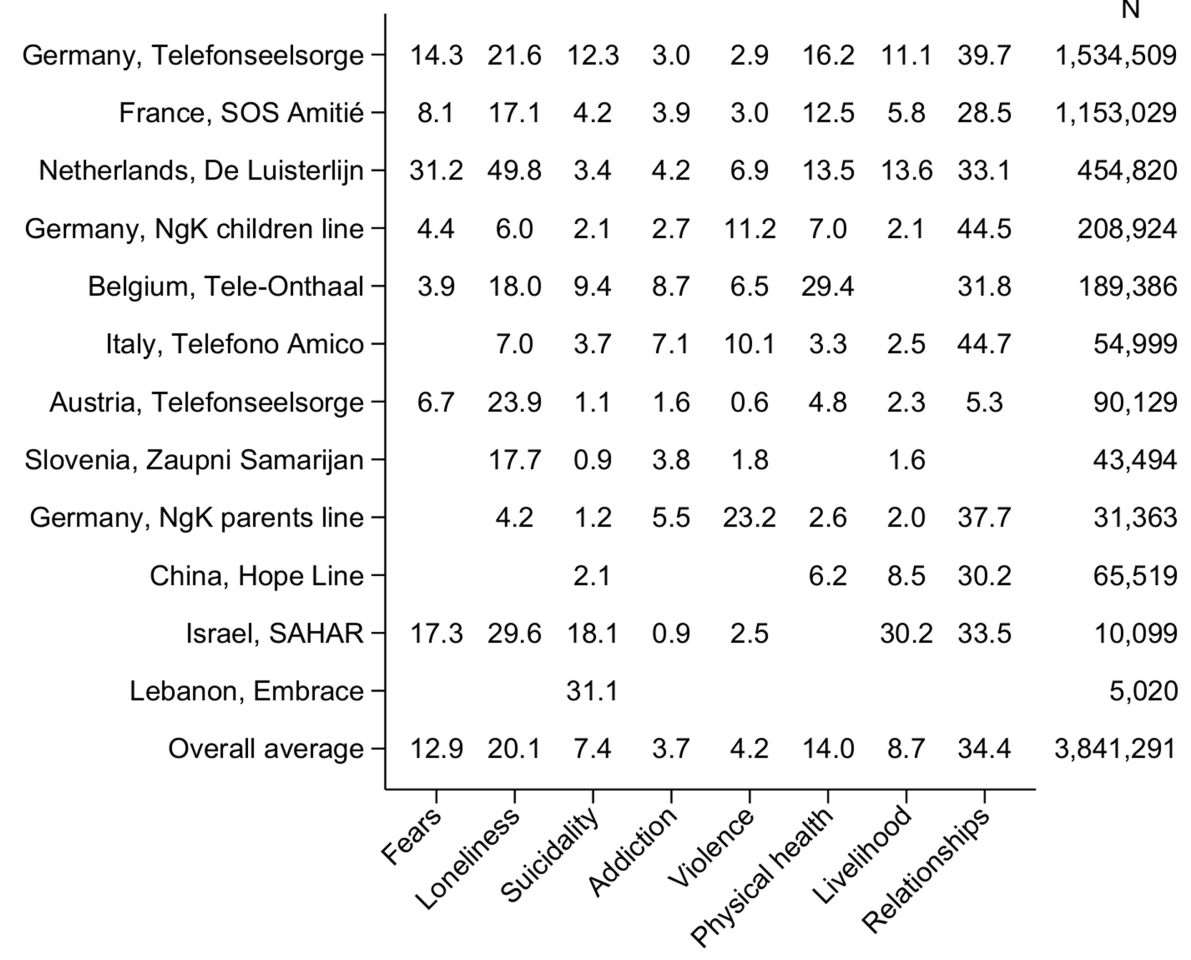

Extended Data Fig. 2 | Conversation topic shares by helpline. Each cell shows the share of calls related to the conversation topic on the horizontal axis, in

covering all calls for which at least on topic was recorded, from 1January 2019 to the respective end of available data, see Extended Data Table 1a and percent of all calls with the helpline indicated on the vertical axis. Full dataset, 


\section{Article}

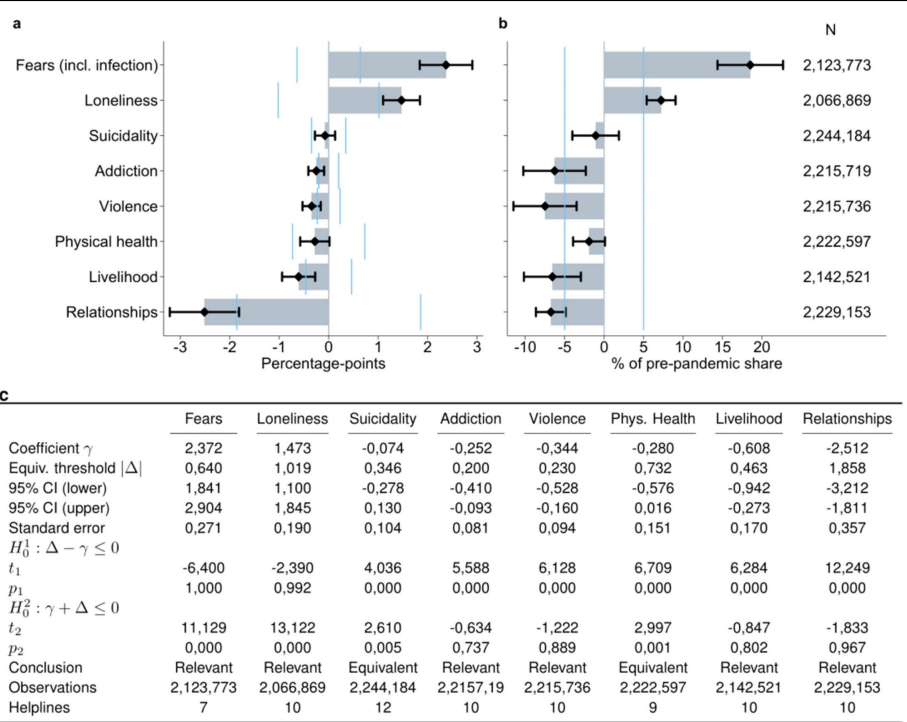

Extended Data Fig. 3 | Magnitude of post-outbreak changes and equivalence tests. a, Coefficient estimates from linear probability models as in Fig.2b, with $95 \%$ confidence intervals and equivalence bounds, defined as $5 \%$ of the pre-pandemic share of the respective topic, indicated by light blue vertical bars. b, Results from a normalized across conversation topics, with coefficient estimates and associated $95 \%$ confidence intervals, and equivalence bounds divided by the pre-pandemic share of calls related to the respective topic.c, Relevance tests, numerical coefficient estimate with corresponding equivalence bounds, with test statistics and $p$-values from two one-sided tests for equivalence. 

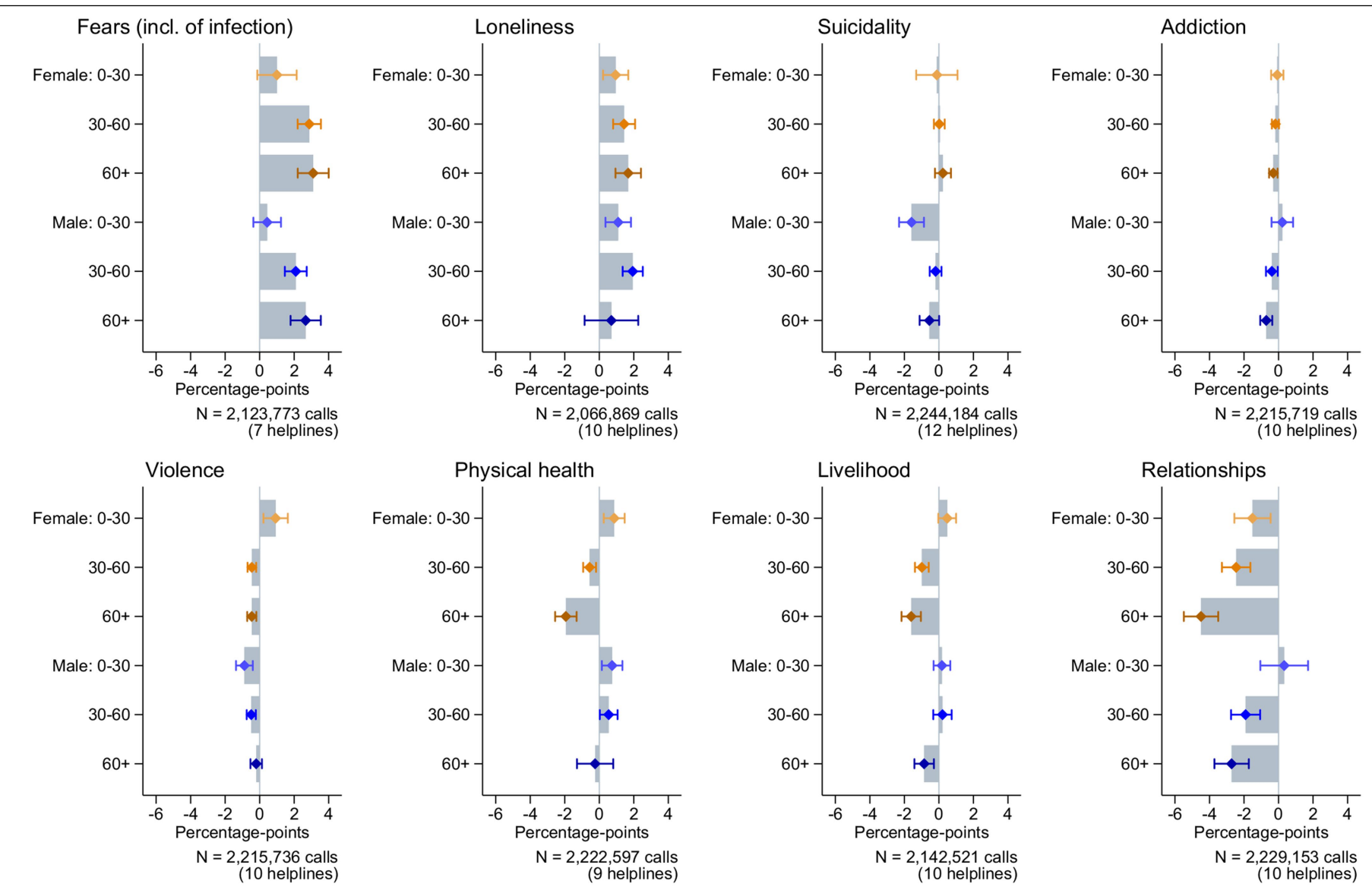

Extended Data Fig. 4 | Change in conversation topics by caller sex and age group. Estimated coefficients for interaction terms of group indicators with Separate linear probability regression models with dependent variable set to one for calls related to the respective topic, see Methods, equation (3) and Supplementary Table 4. 


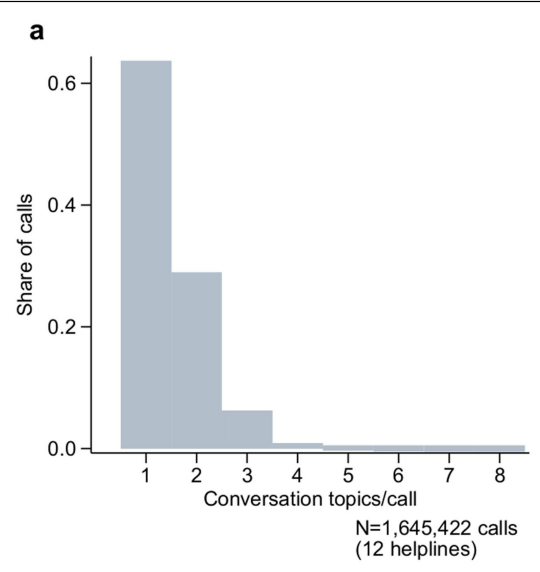

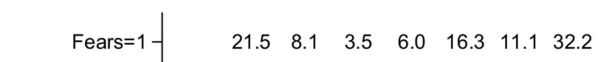

$$
\begin{aligned}
& \begin{array}{l|lllllll}
\text { Loneliness }=1-12.3 & 7.0 & 3.4 & 2.6 & 17.4 & 8.9 & 25.4
\end{array} \\
& \begin{array}{l|lllllll}
\text { Suicidality=1-15.2 } & 19.7 & 5.5 & 6.8 & 14.2 & 8.4 & 31.5
\end{array} \\
& \begin{array}{l|lllllll}
\text { Addiction=1-12.1 } & 18.0 & 9.8 & 6.6 & 11.2 & 8.3 & 30.4
\end{array} \\
& \text { Violence=1- } \begin{array}{llllllll}
18.9 & 12.8 & 10.5 & 5.7 & 8.6 & 8.9 & 39.4
\end{array} \\
& \begin{array}{llllllll}
\text { Physical health }=1-14.9 & 24.0 & 6.9 & 3.0 & 2.7 & 8.2 & 24.5
\end{array} \\
& \text { Livelihood=1-1 } \begin{array}{lllllll}
16.6 & 21.0 & 6.3 & 3.3 & 4.3 & 12.3 & 34.8
\end{array} \\
& \text { Relationships }=1-1 \begin{array}{lllllll}
12.0 & 14.3 & 6.0 & 3.3 & 4.9 & 9.7 & 8.8
\end{array}
\end{aligned}
$$

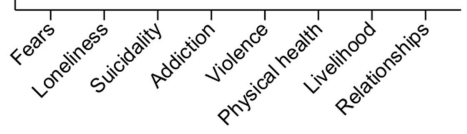

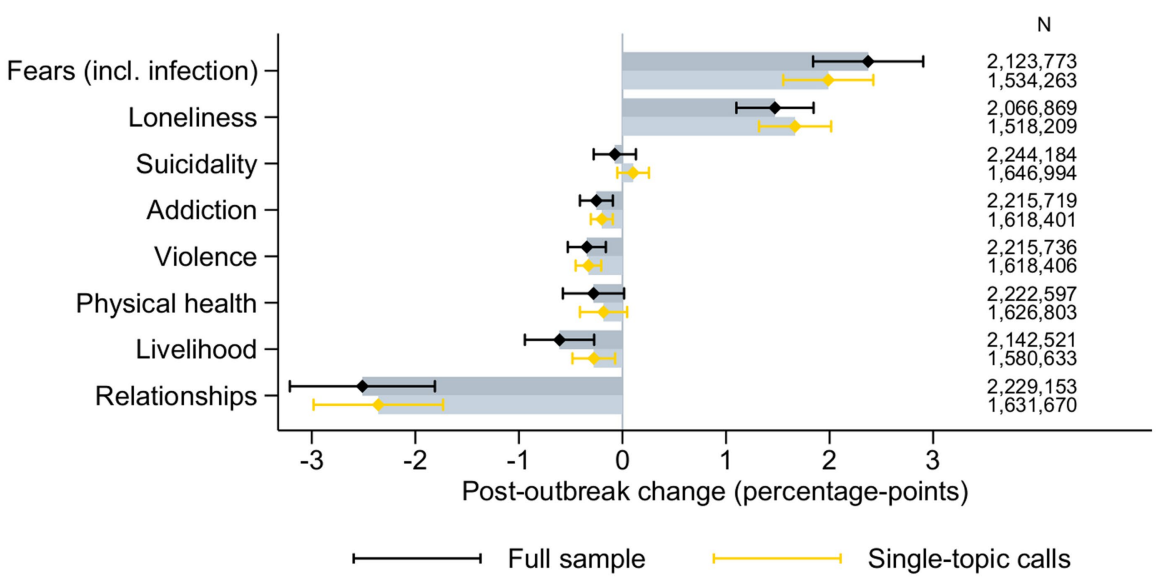

Extended Data Fig. 5 | Non-exclusive conversation topics. Relation among conversation topics for calls included in the estimation sample underlying Fig. 2, from 1January 2019 to 30 June 2020, and where sex and age group of callers are observed. a, Distribution of recorded number of conversation topics per call, b, Overlap in conversation topics, where each row shows the distribution of second or further topics (horizontal axis), in percent of all calls that are related to one specific topic (vertical axis), c, Results from Fig. 2b, with alternative estimates based on a restricted sample of single-topic category calls, see Methods, equation (2). Supplementary Table 5 contains the numerical estimates. 

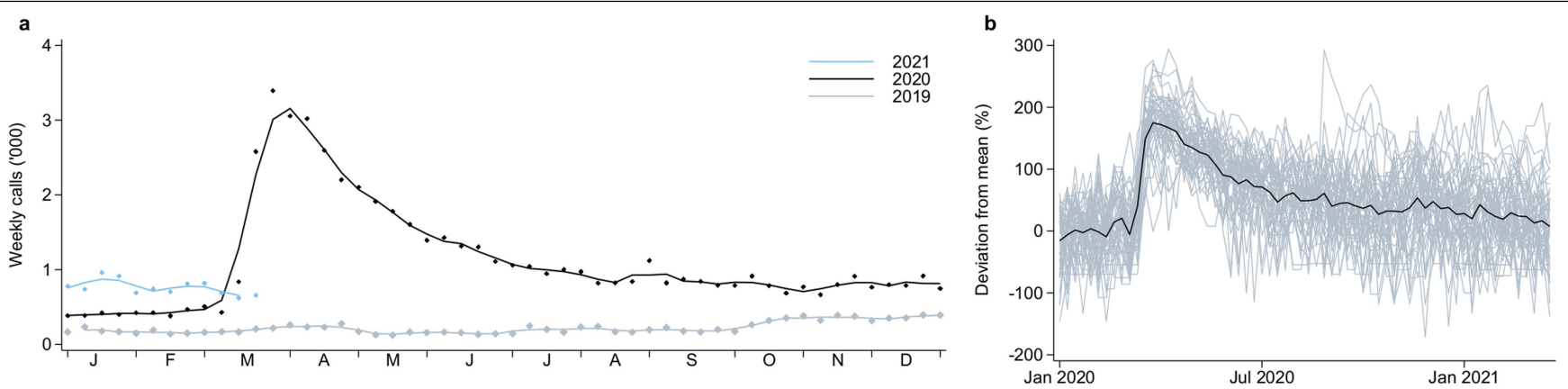

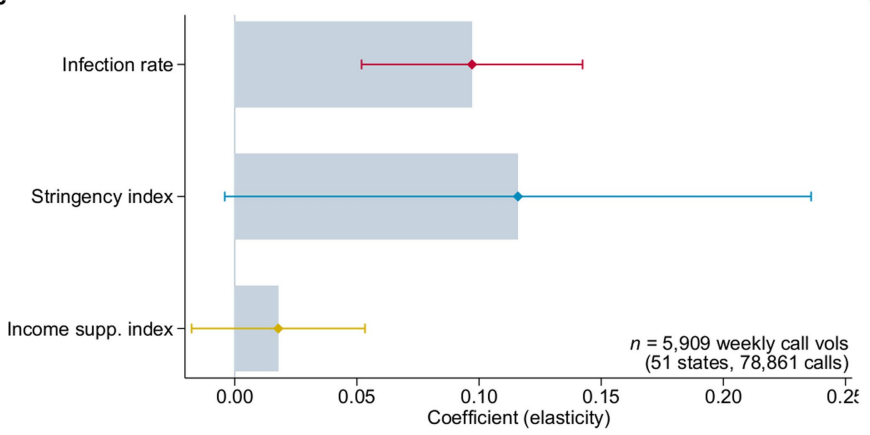

Extended Data Fig. 6 | Disaster Distress Helpline. a, Sum of weekly calls routed to centers by year with 3-week moving average, letters on the horizontal axis indicate calendar months. b, deviation of log calls from time-averaged state-level mean (gray), with overall weekly average (black). c, Estimated coefficients and associated $95 \%$ confidence intervals; sub-national panel model including state and week fixed effects. Dependent variable is

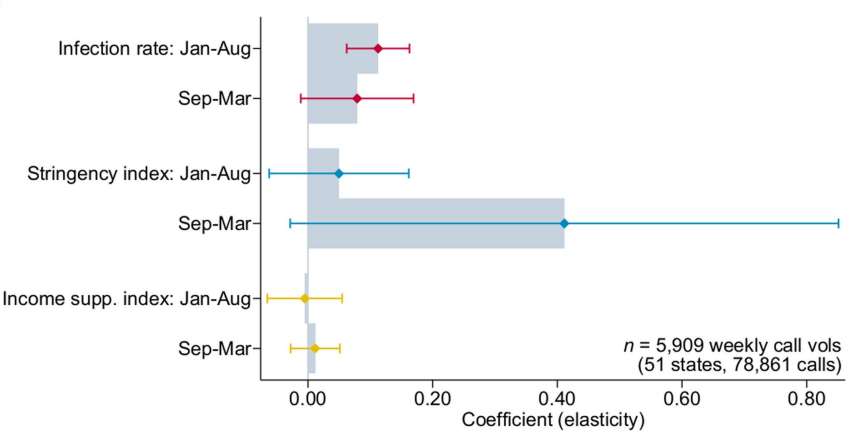

In(Disaster Distress calls +1 ), and independent variables are measured in logs as well; see Methods, equation (5). Supplementary Table 10 contains the numerical estimates. d, Coefficient estimates for interaction terms with indicators for the two periods from January-August 2020 and September 2020-March 2021, and associated $95 \%$ confidence intervals; see Methods, equation (6). Supplementary Table 11 contains the numerical estimates. 
Extended Data Table 1 | Overview over helpline data

\begin{tabular}{|c|c|c|c|c|c|}
\hline & Country & Helpline & Total calls & Data start & Data end \\
\hline \multirow[t]{18}{*}{ a } & Germany & Telefonseelsorge Deutschland & $1,500,938$ & 01.01 .2019 & 31.03 .2021 \\
\hline & France & S.O.S. Amitié & $1,153,029$ & 01.01 .2019 & 31.03 .2021 \\
\hline & Netherlands & De Luisterlijn & 454,820 & 01.01 .2019 & 30.06 .2020 \\
\hline & Germany & Nr. gegen Kummer (children) & 208,924 & 01.01 .2019 & 18.02.2021 \\
\hline & Belgium & Tele-Onthaal & 189,386 & 01.01 .2019 & 28.06 .2020 \\
\hline & Austria & Telefonseelsorge österreich & 89,619 & 01.01 .2019 & 30.06 .2020 \\
\hline & China & Hope Line & 65,519 & 01.01 .2019 & 25.06 .2020 \\
\hline & Italy & Telefono Amico & 54,999 & 01.01 .2019 & 01.06 .2020 \\
\hline & Slovenia & Zaupni telefon Samarijan & 43,494 & 01.01 .2019 & 14.01 .2021 \\
\hline & Germany & Nr. gegen Kummer (parents) & 31,363 & 01.01 .2019 & 18.02.2021 \\
\hline & Czech Republic & Modrá linka & 19,871 & 01.01 .2019 & 12.06 .2020 \\
\hline & Israel & SAHAR Emotional support chat & 15,956 & 01.01 .2020 & 24.12 .2020 \\
\hline & Portugal & S.O.S. Voz Amiga & 9,930 & 02.01 .2019 & 15.06 .2020 \\
\hline & Germany & Muslimisches Seelsorgetelefon & 5,485 & 01.01 .2020 & 08.12 .2020 \\
\hline & Lebanon & Embrace Lifeline & 5,020 & 02.01 .2019 & 01.07 .2020 \\
\hline & Luxembourg & SOS Détresse & 1,928 & 01.01 .2020 & 21.06 .2020 \\
\hline & Bosnia Herzeg. & Plavi Telefon & 1,034 & 01.01 .2019 & 23.10 .2020 \\
\hline & Hong Kong & Samaritan Befrienders & 635 & 23.01 .2020 & 06.10 .2020 \\
\hline \multirow[t]{3}{*}{ b } & Switzerland & Die Dargebotene Hand & 110,177 & 28.02 .2019 & 30.06 .2020 \\
\hline & Hungary & LESZ & 79,491 & 01.01 .2019 & 31.05 .2020 \\
\hline & Finland & MIELI Mental Health & 32,148 & 01.01 .2020 & 30.06 .2020 \\
\hline \multirow[t]{3}{*}{ c } & United States & National Suicide Prevention Lifeline & $3,858,039$ & 01.01 .2019 & 21.03 .2021 \\
\hline & & Disaster Distress Helpline & 78,861 & 01.01 .2019 & 21.03 .2021 \\
\hline & 19 countries & 23 helplines & $8,010,666$ & & \\
\hline
\end{tabular}

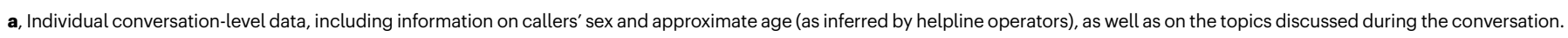
b, Daily conversation volumes, by sex, age, and topic. c, Sub-national weekly call volumes across US States (raw number of calls routed to local centers). 
Extended Data Table 2 | Caller characteristics before and after the pandemic outbreak

\begin{tabular}{|c|c|c|c|c|c|c|c|c|c|c|c|c|}
\hline \multirow[b]{2}{*}{ Country } & \multirow[b]{2}{*}{ Helpline } & \multicolumn{2}{|c|}{ Female } & \multicolumn{2}{|c|}{ Age $<30$} & \multicolumn{2}{|c|}{ Age $>60$} & \multicolumn{2}{|c|}{ Voice call } & \multicolumn{2}{|c|}{ Known caller } & \multirow[b]{2}{*}{$\mathrm{N}$ (calls) } \\
\hline & & pre & post & pre & post & pre & post & pre & post & pre & post & \\
\hline Germany & Telefonseelsorge & 68.6 & 68.4 & 15.5 & 14.8 & 29.0 & 31.2 & 88.6 & 90.2 & . & . & $1,534,509$ \\
\hline France & S.O.S. Amitié & 54.0 & 55.8 & 4.3 & 5.2 & 17.9 & 18.0 & 95.8 & 95.7 & . & . & $1,153,029$ \\
\hline Netherlands & De Luisterlijn & 65.9 & 66.6 & 8.9 & 8.6 & 18.4 & 23.7 & 90.9 & 90.3 & . & . & 454,820 \\
\hline Germany & NgK children line & 39.1 & 40.7 & 100 & 100 & 0 & 0 & 100 & 100 & 11.8 & 10.2 & 208,924 \\
\hline Belgium & Tele-Onthaal & 66.5 & 67.3 & 13.3 & 15.6 & 28.6 & 30.2 & 87.0 & 86.0 & 42.9 & 41.3 & 189,386 \\
\hline Austria & Telefonseelsorge & 67.3 & 62.7 & 9.1 & 8.1 & 31.8 & 36.3 & 100 & 100 & . & - & 90,129 \\
\hline China & Hope Line & 49.2 & 54.7 & 61.6 & 66.1 & 0.4 & 0.3 & 100 & 100 & 29.6 & 31.4 & 65,519 \\
\hline Italy & Telefono Amico & 43.3 & 34.5 & 5.5 & 7.2 & 9.7 & 6.3 & 98.1 & 92.4 & . & . & 54,999 \\
\hline Slovenia & Zaupni Samarijan & 45.6 & 48.7 & 0.7 & 0.6 & 8.9 & 9.8 & 100 & 100 & . & . & 43,494 \\
\hline Germany & NgK parent line & 74.8 & 73.4 & 11.4 & 10.7 & 8.4 & 7.5 & 100 & 100 & 10.3 & 9.0 & 31,363 \\
\hline Israel & Sahar & 66.8 & 69.3 & 38.5 & 41.2 & 1.1 & 1.5 & 0 & 0 & 50.7 & 40.8 & 10,099 \\
\hline Lebanon & Embrace & 56.5 & 50.6 & 74.1 & 56.2 & 4.6 & 9.7 & 100 & 100 & 11.5 & 17.6 & 5,020 \\
\hline
\end{tabular}

Shares of callers belonging to the category indicated in the column header in percent of all calls to the respective helpline, pre and post March 1,2020 . Full dataset, covering calls from 1 January 2019 to the respective end of available data, see Extended Data Table 1a. Caller sex and age are not observed for all calls. Voice calls include phone and Voice-Over-IP calls, as opposed to text based conversations (online chats, messaging apps). Known callers are defined as individuals who repeatedly call the helpline and are therefore known to staff.

Further details on individual helplines are available in Supplementary Figs. 2-35. 


\section{nature portfolio}

Double-blind peer review submissions: write $D B P R$ and your manuscript number here

Corresponding author(s): instead of author names.

Last updated by author(s): YYYY-MM-DD

\section{Reporting Summary}

Nature Portfolio wishes to improve the reproducibility of the work that we publish. This form provides structure for consistency and transparency in reporting. For further information on Nature Portfolio policies, see our Editorial Policies and the Editorial Policy Checklist.

\section{Statistics}

For all statistical analyses, confirm that the following items are present in the figure legend, table legend, main text, or Methods section.

n/a Confirmed

$\square$ The exact sample size $(n)$ for each experimental group/condition, given as a discrete number and unit of measurement

\A statement on whether measurements were taken from distinct samples or whether the same sample was measured repeatedly

Х The statistical test(s) used AND whether they are one- or two-sided

Only common tests should be described solely by name; describe more complex techniques in the Methods section.

$\bigotimes$ A description of all covariates tested

Х $\square$ A description of any assumptions or corrections, such as tests of normality and adjustment for multiple comparisons

A full description of the statistical parameters including central tendency (e.g. means) or other basic estimates (e.g. regression coefficient)

AND variation (e.g. standard deviation) or associated estimates of uncertainty (e.g. confidence intervals)

$\varnothing$ For null hypothesis testing, the test statistic (e.g. $F, t, r$ ) with confidence intervals, effect sizes, degrees of freedom and $P$ value noted Give $P$ values as exact values whenever suitable.

\ $\square$ For Bayesian analysis, information on the choice of priors and Markov chain Monte Carlo settings

Х $\square$ For hierarchical and complex designs, identification of the appropriate level for tests and full reporting of outcomes

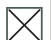
Estimates of effect sizes (e.g. Cohen's $d$, Pearson's $r$ ), indicating how they were calculated

Our web collection on statistics for biologists contains articles on many of the points above.

\section{Software and code}

Policy information about availability of computer code

Data collection Data from helplines was obtained via email or file-sharing platforms. Files were prepared in MS Excel 2016 and Notepad++ v7.9.5 and combined using Stata/SE 17.0.

Data analysis Files were collected in MS Excel 2016 and Notepad++ v7.9.5. Data preparation and analysis was carried out in Stata/SE 17.0, Do-files are available online at https://doi.org/10.5281/zenodo.5495830

For manuscripts utilizing custom algorithms or software that are central to the research but not yet described in published literature, software must be made available to editors and reviewers. We strongly encourage code deposition in a community repository (e.g. GitHub). See the Nature Portfolio guidelines for submitting code \& software for further information.

\section{Data}

Policy information about availability of data

All manuscripts must include a data availability statement. This statement should provide the following information, where applicable:

- Accession codes, unique identifiers, or web links for publicly available datasets

- A description of any restrictions on data availability

- For clinical datasets or third party data, please ensure that the statement adheres to our policy

Data were provided by helplines for the sole purpose of this research project, subject to confidentiality agreements. The full data underlying specific parts of the analysis is available from the authors upon reasonable request and conditional on permission of the respective helplines. Figure source data is provided with this paper. To obtain (updated) helpline data, researchers have to sign agreements with individual helplines, for further information, contact: presse@telefonseelsorge.de (Telefonseelsorge DE), contact@sosamitieparisidf.fr (S.O.S. Amitié), info@deluisterlijn.nl (De Luisterlijn), info@nummergegenkummer.de (Nr. gegen Kummer), federatie@tele-onthaal.be (Tele-Onthaal), telefonseelsorge@edw.or.at (Telefonseelsorge AT), 
Icicenter@163.com(Hope Line), telefonoamico@telefonoamico.it (Telefono Amico), samarijan@gmail.com (Zaupni Samarijan),hana.regnerova@modralinka.cz (Modrá linka), support@sahar.org.il (Sahar), direccaolphm@gmail.com (S.O.S.Voz Amiga), info@mutes.de (Muslim. Seels.), info@embracelebanon.org (Embrace), info@sosdetresse.lu (SOS Détresse), info@novageneracija.org (PlaviTelefon), sbhkinfo@sbhk.org.hk (Samaritan Befrienders), verband@143.ch (Die Dargebotene Hand), soskeskus@mieli.fi (MIELImental health), lesziroda@gmail.com(LESZ), info@vibrant.org, (Lifeline and Disaster Distress Helpline). Data on infection rates and policy measures is publicly available online from the JHU CSSE COVID-19 Dataset at https://github.com/CSSEGISandData, and the Oxford Covid-19 Government Response Tracker at https://github.com/OxCGRT.

\section{Field-specific reporting}

Please select the one below that is the best fit for your research. If you are not sure, read the appropriate sections before making your selection.

Life sciences

$\bigotimes$ Behavioural \& social sciences

Ecological, evolutionary \& environmental sciences

For a reference copy of the document with all sections, see nature.com/documents/nr-reporting-summary-flat.pdf

\section{Behavioural \& social sciences study design}

All studies must disclose on these points even when the disclosure is negative.

Study description

Research sample

Sampling strategy

Data collection

Timing

Data exclusions

Non-participation

Randomization
We analyze quantitative data on the number and characteristics of calls to helplines. These are field data produced by the helplines themselves. Our contribution consists in assembling those data across 19 countries and statistically analyzing them, with a particular focus on the Covid-19 pandemic.

The sample is self-selected, as it consists of callers to helplines. This has the advantage of capturing what we call "revealed anxiety": by calling a helpline (unlike e.g. ticking a box on a survey questionnaire), respondents incur a mental and/or time cost that implies their concern to be real. A limitation of this approach is that we do not observe socio-demographic characteristics of callers, because they are anonymous. This is why we focus on longitudinal analyses: when looking at changes in call patterns over time, the timeinvariant characteristics of the caller population are "filtered out". All these issues are discussed in the paper.

The sample is self-selected, as it consists of callers to helplines.

The selection of sample helplines was based (a) on an internet search of well-documented helplines and (b) on receiving data from those helplines. Of 154 helplines contacted, we received data from 37 helplines. Where possible, we requested data from 1 January 2019 to the most recent available date, in order to allow a comparison of call patterns after the COVID19 outbreak to call patterns at the same time of year pre-pandemic. The information obtained from 23 helplines was of sufficiently detailed coverage and consistency to be included in our pooled analyses. All this information is provided in the paper.

The maximum time span covered by the data is 1 January 2019 to 31 March 2021. We started collecting the data from helplines in April 2020 and expanded/updated the collection effort up until May 2021.

Among the helplines included in the paper, we did not exclude any data, except that, where possible, we dropped calls that were unambiguously labelled by the helplines as "hoax calls".

This issue does not apply to our setting, as we use observational data from helplines.

The sample is self-selected, as it consists of callers to helplines. We focus on longitudinal analyses: when looking at changes in call patterns over time, the timeinvariant characteristics of the caller population are "filtered out", which should minimize potential selection bias.

\section{Reporting for specific materials, systems and methods}

We require information from authors about some types of materials, experimental systems and methods used in many studies. Here, indicate whether each material, system or method listed is relevant to your study. If you are not sure if a list item applies to your research, read the appropriate section before selecting a response.

\begin{tabular}{l|l|l} 
Materials \& experimental systems \\
\hline $\mathrm{n} / \mathrm{a}$ & Involved in the study \\
\hline & $\square$ Antibodies \\
\hline & $\square$ Eukaryotic cell lines \\
$\square$ & $\square$ Animaeontology and archaeology \\
$\square$ & $\square$ Clinical data \\
\hline & $\square$ Dual use research of concern
\end{tabular}

\begin{tabular}{l|l}
\multicolumn{2}{l}{ Methods } \\
\hline n/a & Involved in the study \\
$\square$ & $\square$ ChIP-seq \\
$\square$ & $\square$ Flow cytometry \\
$\square$ & $\square$ MRI-based neuroimaging
\end{tabular}

n/a $\mid$ Involved in the study

$\square$ ChIP-sec

Х $\square$ MRI-based neuroimaging 
Policy information about studies involving human research participants

Population characteristics

The underlying population is the sum of people living in the countries served by our sample helplines and old enough to place a call.

Recruitment

Ethics oversight

\section{Callers self-selected into calling}

Data processing and analysis were conducted according to the guidelines of the Internal Review Board (IRB) of the Faculty of Business and Economics at the University of Lausanne. Two considerations were important. First, all helplines guarantee anonymity to their callers, both toward their operators and toward the outside world. Names and addresses are never asked, and caller numbers are hidden by the system. It is therefore impossible to identify callers even from the call-level data provided by a subset of helplines. Anonymous data is not covered by data protection considerations. Second, most helplines explicitly inform callers that anonymous call data are recorded and made available for reporting and statistical purposes. The analysis of those data conforms with the aim of the Ethics Charter of the International Federation of Telephone Emergency Services (IFOTES), which aims to "(c)ollect and disseminate data gathered by the Branches in connection with the challenges facingMental Health and Prevention of Suicide", and to "(a)ssist and encourage research carried out in these fields". The IRB exempted the study from a full review owing to the secondary nature of the data used.

Note that full information on the approval of the study protocol must also be provided in the manuscript. 